\title{
Whole genome sequencing of Streptococcus pneumoniae: Development, evaluation and verification of targets for serogroup and serotype prediction using an automated pipeline
}

\author{
Georgia Kapatai ${ }^{\text {Corresp.., }}{ }^{1}$ ， Carmen L Sheppard ${ }^{1}$ ， Ali Al-Shahib ${ }^{2}$ ， David J Litt ${ }^{1}$ ， Anthony P Underwood ${ }^{2}$, \\ Timothy G Harrison ${ }^{1}$, Norman K Fry ${ }^{1}$ \\ ${ }^{1}$ Respiratory and Vaccine Preventable Bacterial Reference Unit, Public Health England, London, United Kingdom \\ 2 Infectious Disease Informatics, Public Health England, London, United Kingdom \\ Corresponding Author: Georgia Kapatai \\ Email address: Georgia.Kapatai@phe.gov.uk
}

Streptococcus pneumoniae typically express one of 92 serologically distinct capsule polysaccharide (cps) types (serotypes). Some of these serotypes are closely related to each other; using the commercially available typing antisera these are assigned to common serogroups containing types that show crossreactivity. In this serotyping scheme, factor antisera are used to allocate serotypes within a serogroup, based on patterns of reactions. This serotyping method is technically demanding, requires considerable experience and the reading of the results can be subjective.

This study describes the analysis of the S. pneumoniae capsular operon genetic sequence to determine serotype distinguishing features and the development, evaluation and verification of an automated whole genome sequence (WGS)-based serotyping bioinformatics tool, PneumoCaT (Pneumococcal Capsule Typing).

Initially, WGS data from 871 S. pneumoniae isolates were mapped to reference cps locus sequences for the 92 serotypes. Thirty-two of 92 serotypes could be unambiguously identified based on sequence similarities within the cps operon. The remaining 60 were allocated to one of 20 'genogroups' that broadly correspond to the immunologically defined serogroups. By comparing the cps reference sequences for each genogroup, unique molecular differences were determined for serotypes within 18 of the 20 genogroups and verified using the set of 871 isolates. This information was used to design a decision-tree style algorithm within the PneumoCaT bioinformatics tool to predict to serotype level for 89/94 (92 + 2 molecular types/subtypes) from WGS data and to serogroup level for serogroups 24 and 32 , which currently comprise $2.1 \%$ of UK referred, invasive isolates submitted to the National Reference Laboratory (NRL), Public Health England (June 2014 - July 2015). PneumoCaT was evaluated with an internal validation set of 2065 UK isolates covering 72/92 serotypes, including 19 non-typeable isolates and an external validation set of 2964 isolates from Thailand $(n=2531)$, USA $(n=181)$ and Iceland $(n=252)$. PneumoCaT was able to predict serotype in $99.1 \%$ of the typeable UK isolates and in $99.0 \%$ of the non-UK isolates. Concordance was evaluated in UK isolates where further investigation was possible; in $91.5 \%$ of the cases the predicted capsular type was concordant with the serologically derived serotype. Following retesting, concordance increased to $99.3 \%$ and in most resolved cases $(97.8 \%$; 135/138) discordance was shown to be caused by errors in original serotyping. Replicate testing demonstrated that PneumoCaT gave $100 \%$ reproducibility of the predicted serotype result.

In summary, we have developed a WGS-based serotyping method that can predict capsular type to 
serotype level for 89/94 serotypes and to serogroup level for the remaining four. This approach could be integrated into routine typing workflows in reference laboratories, reducing the need for phenotypic immunological testing. 
1 Whole Genome Sequencing of Streptococcus pneumoniae:

2 Development, Evaluation and Verification of Targets for

3 Serogroup and Serotype Prediction using an Automated

4 Pipeline

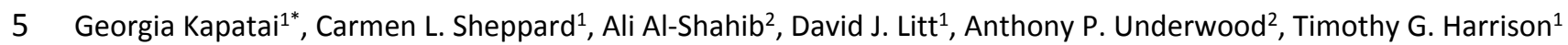

6 and Norman K. Fry ${ }^{1}$.

7

${ }^{1}$ Respiratory and Vaccine Preventable Bacterial Reference Unit, Microbiology Services Colindale, Public Health

England

${ }^{2}$ Infectious Disease Informatics, Microbiology Services Colindale, Public Health England

* Corresponding author 


\section{Introduction}

28

29

30

31

Streptococcus pneumoniae is a human respiratory tract pathogen that represents a leading cause of invasive bacterial disease in children under 5 years of age and the elderly. Isolates of $S$. pneumoniae are traditionally characterised in terms of the antigenicity of their capsular polysaccharides (CPS) and currently there are 92 serologically distinct serotypes as defined by Statens Serum Institut (SSI), Copenhagen, Denmark sera using the Neufeld reaction for capsular swelling (referred to as Quellung)(Austrian; Statens Serum Institut, 2013). Additional 'serotypes' $(6 \mathrm{E}, 6 \mathrm{~F}, 6 \mathrm{G}, 6 \mathrm{H}, 11 \mathrm{E}, 20 \mathrm{~A}$ and $20 \mathrm{~B})$ have been identified by molecular methods and/or monoclonal antibodies, but these are not distinguishable using the current commercial serotyping sera and some may not be phenotypically distinct types, but simply genetic variants producing the same polysaccharide structures (Calix \& Nahm, 2010; Calix et al., 2012; Ko, Baek \& Song, 2013a; Oliver et al., 2013a; Park et al., 2015; Burton et al., 2016). The polysaccharide capsule is also the target of all currently licensed vaccines and therefore, due to selective pressure on circulating strains, accurate identification of pneumococcal serotypes is essential for disease surveillance, evaluation of the efficacy of the pneumococcal vaccines and to inform national vaccine policy.

In the UK, the initial reduction of invasive pneumococcal disease (IPD) and carriage, due to the introduction of PCV7 and PCV13 polysaccharide-conjugate vaccines, was followed by increases in non-vaccine type IPD(Miller et al., 2011; Waight et al., 2015). Specifically, following implementation of pneumococcal conjugate vaccine PCV13(Centers for Disease Control and Prevention (CDC)., 2010) in 2010, changes in disease-causing serotypes included a significant reduction in PCV13 serotypes 1, 6A, 7F and 19A, followed by a substantial increase in non- 
49 vaccine serotypes $8,12 \mathrm{~F}, 15 \mathrm{~A}, 15 \mathrm{~B} / \mathrm{C}, 22 \mathrm{~F}, 23 \mathrm{~B}$ and $24 \mathrm{~F}$ observed in 2013/14 in children under

505 years of age, when compared with 2012/13 (Waight et al., 2015) (Figure 1). Surveillance

51 studies from other countries revealed a similar pattern of PCV13-serotype reduction and non-

52 vaccine serotype increase in IPD cases. These studies underline the need for continuous

53 surveillance to monitor the emergence of serotypes due to the clonal expansion of non-vaccine

54 serotypes (Richter et al., 2013; Regev-Yochay G., Paran Y., Bishara J., Oren I., Chowers M.,

55 Tziba Y., Istomin V., Weinberger M., Miron D., Temper V., 2015).

56 The Quellung reaction, in conjunction with the antisera from SSI, is currently considered the

57 gold standard for pneumococcal capsular typing and can identify all 92 serotypes (Austrian;

58 Habib, Porter \& Satzke, 2014). Agglutination tests were developed later to reduce the time

59 required to serotype a batch of isolates by eliminating the need for microscopy. In these tests SSI

60 antisera reacts with the pneumococcal capsule and produces visible clumping (Kronvall G, 1973;

61 Porter, Ortika \& Satzke, 2014). Based on the SSI serotype scheme there are 25 distinct serotypes

62 and 21 serogroups, each consisting of between 2 and 5 immunologically-related serotypes,

63 accounting for a further 67 serotypes (Statens Serum Institut, 2013). Despite the wide use of the

64 SSI sera, the serological methods can be difficult to interpret since, in certain cases, serotypes

65 within a serogroup can cross-react with some of the antisera making it impossible to resolve to

66 serotype level. In these cases, the serotypes are reported to serogroup level (Jauneikaite et al.,

67 2015).

68 In 2006, Bentley et al. (Bentley et al., 2006), reported the sequences of the capsular biosynthetic

69 loci of 90 pneumococcal serotypes (serotypes 6C and 6D were not included) and linked the

70 capsular gene sequences to known structural and immunological patterns, thus paving the way

71 for molecular capsular typing. Since then, new molecular serotyping methods have been 
72 described (microarray (Turner et al., 2011), multiplex PCR (Brito, Ramirez \& Lencastre, 2003),

73 in silico inference from WGS data (Croucher et al., 2011; Everett et al., 2012; Metcalf et al., 74 2016)), utilising the molecular differences between the capsular loci to determine serotype 75 (Jauneikaite et al., 2015). A review of methodologies for capsular typing of S. pneumoniae 76 including serological assays, semi-automated molecular tests, and one directly from WGS 77 data(Liyanapathirana et al., 2014) was published by Jauneikaite et al ${ }^{14}$. These molecular/WGS 78 assays have some advantages compared to the serological methods described above: easier 79 interpretation, multiplex capability and in some cases no requirement for culture. However, they 80 still have some limitations, especially if they were to be used for surveillance. Firstly, due to the 81 genetic similarities of certain serotypes, not all serogroups can be resolved. Secondly, most 82 assays described to date only include the most common serotypes so currently not all serotypes can be detected (Magomani et al., 2014). Here we describe genetic capsular locus differences for

84 all but four serotypes and demonstrate the use of these differences in predicting capsular type 85 from WGS data using an automated bioinformatics tool that can be incorporated into routine 86 workflows.

\section{Materials and Methods}

Isolate selection

Reference strains ( $\mathrm{n}=91$ ) for all serotypes (excluding 6D) were acquired from Statens Serum

91 Institut. Reference strain for 6D was kindly provided by The National Institute for Health and

92 Welfare (THL), Finland. A total of 926 clinical isolates were selected from the archives of the

93 Public Health England (PHE) National Reference Lab as a test cohort; for serotypes found to 94 belong to a genogroup, at least 10 isolates were selected where available. Post genomic-sequence 
95 data cleansing (to remove repeat isolates from the same patient, mixed cultures, other species and

96 MLST partial profiles or failures) resulted in 871 isolates (Development Set in Table 1). In

97 addition, 2079 prospective or research-related isolates were sequenced as part of the UK

98 validation cohort. This cohort covers 72 of the commonly circulating serotypes (including all

99 vaccine serotypes), and includes prospective isolates received by PHE during 2015, isolates

100 selected as part of research projects and epidemiological investigations (15A $(n=196)$ and 19A

101 ( $n=249)$, respectively) and archived isolates for rarer serotypes. Post genomic-sequence data

102 cleansing of this dataset resulted in a total of 2065 isolates (Validation Set in Table 1). All

103 isolates were serotyped on receipt as part of the PHE enhanced surveillance programme using

104 slide agglutination with Statens Serum Institut typing sera.

105 Genomic data for non-UK isolates were obtained from Streptococcus pneumoniae isolate 106 database hosted in BIGSdb (http://pubmlst.org/software/database/bigsdb/)(Jolley \& Maiden, 107 2010) and the European Nucleotide Archive (ENA; http://www.ebi.ac.uk/ena). Specifically, 108 three collections were used; a set of 2531 isolates from Thailand initially described by 109 Chewapreecha et al(Chewapreecha et al., 2014), an Icelandic panel of 252 serogroup 6 isolates 110 described in van Tonder et al(van Tonder et al., 2015) and a USA panel of 181 invasive isolates

111 available in ENA as study SRP059723.

\section{DNA extraction and sequencing}

113 Isolates were grown overnight on horse blood agar (PHE Media Services) with 5\% $\mathrm{CO}_{2}$. DNA 114 was extracted from an entire plate of growth for each isolate using the QIAsymphony SP 115 automated instrument (Qiagen) and QIAsymphony DSP DNA Mini Kit, using the 116 manufacturer's recommended tissue extraction protocol for Gram negative bacteria (including a 1171 hour pre-incubation with proteinase $\mathrm{K}$ in ATL buffer and RNAse A treatment). DNA 
118 concentrations were measured using the Quant-iT dsDNA Broad-Range Assay Kit (Life

119 Technologies, Paisley, UK) and GloMax ${ }^{\circledR} 96$ Microplate Luminometer (Promega, Southampton,

120 UK). DNA was sent for whole genome sequencing (WGS) by Illumina sequencing using the

121 PHE Genomic Services and Development Unit (Colindale, UK) (Dallman et al., 2014). Illumina

122 Nextera DNA libraries were constructed and sequenced using the Illumina HiSeq 2500.

124 Casava 1.8.2 (Illumina inc. San Diego, CA,USA) was used to deplex the samples and FASTQ 125 reads were processed with Trimmomatic (Bolger, Lohse \& Usadel, 2014) to remove bases from 126 the trailing end that fall below a PHRED score of 30. K-mer identification software 127 (https://github.com/phe-bioinformatics/kmerid) was used to compare the sequence reads with a 128 panel of curated NCBI Refseq genomes to identify the species. A sample of k-mers (DNA 129 sequences of length $\mathrm{k}$ ) in the sequence data are compared against the k-mers of 1769 reference 130 genomes representing 59 pathogenic genera obtained from RefSeq. The closest percentage match 131 is identified, and provides initial confirmation of the species. This step also identifies samples 132 containing more than one species of bacteria (i.e. mixed cultures) and any bacteria misidentified 133 as Streptococcus pneumoniae by the sending laboratory. Further analysis continued only if $S$. 134 pneumoniae was identified. FASTQ reads from all sequences in this study were submitted to 135 ENA using the ena_submission tool (https://github.com/phe-bioinformatics/ena_submission) and 136 can be found at the PHE Pathogens BioProject PRJEB14267 at ENA 137 (http://www.ebi.ac.uk/ena/data/view/PRJEB14267; Supplementary tables S1-2).

\section{Polysaccharide capsule operon locus sequence analysis}

139 GenBank and FASTA files for the capsular locus sequences for the 90 serotypes published by 140 Bentley et al. (Bentley et al., 2006) were retrieved from NCBI (http://www.ncbi.nlm.nih.gov/) 
141 using accession numbers CR931632-CR931722(Bentley et al., 2006). For serotypes 6C and 6D

142 accession numbers JF911515.1 and HV580364.1 were used, respectively. Capsular locus

143 sequences for $6 \mathrm{E}$ and $23 \mathrm{~B} 1$, a new $23 \mathrm{~B}$ genetic subtype identified during the course of this

144 project, were derived in-house using the assembly-based approach described below. Isolates for

145 both types $(6 \mathrm{E} \mathrm{n}=12 ; 23 \mathrm{~B} 1 \mathrm{n}=27)$ were assembled using SPAdes(Bankevich et al., 2012) and the

146 capsular locus sequences were extracted using the sequence for $6 \mathrm{~B}$ and $23 \mathrm{~B}$, respectively. The

147 extracted sequences were aligned using ClustalW(Thompson, Higgins \& Gibson, 1994) and the

148 alignment was visualized with MEGA6(Tamura et al., 2013). Based on the alignment, consensus

149 sequences were derived for each type and submitted to ENA as assemblies under PHE Pathogens

150 BioProject PRJEB14267 with accession numbers LT594598.1 and LT594599.1 for 6E and 23B1,

151 respectively. Using the GenBank annotation, gene sequences were retrieved from all capsular

152 types. BLAST+ (version 2.2.27)(Camacho et al., 2009) alignment was then used to detect gene-

153 level differences within each genogroup.

154 Capsular typing tool implementation

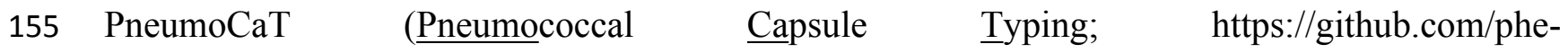

156 bioinformatics/PneumoCaT), written in Python (version 2.7.6), utilises a two-step method to

157 assign capsular type (Figure 2). In the first step, reads from each readset are mapped to a multi-

158 fasta file containing 94 capsular locus sequences (92 serologically distinct serotypes +2

159 molecular types/subtypes - 6E and 23B1) using bowtie2 (version 2.1.0; following options used: -

160 -fr --minins 300 --maxins 1100 -k 99999 -D 20 -R 3 -N 0 -L 20 -I S, 1,0.50) (Langmead B. and

161 Salzberg S., 2012). Thresholds of coverage of $>90 \%$ of the length of the sequence, minimum

162 depth of 5 reads per bp and a mean depth of $>20$ reads over the entire length of the sequence are 
163 implemented during this step. This step is considered successful if one or more capsular locus 164 sequences are returned.

165 If a match to a single capsular locus is returned and the capsular type predicted does not belong 166 to one of our defined genogroups (Table 2), then the software terminates here and reports this as 167 the predicted capsular type (Figure 3). If the match belongs to a genogroup or more than one 168 locus is matched then the software moves to the second step; a variant-based approach. If 169 multiple serotypes are matched in step 1 and they do not correspond to the same genogroup then 170 a 'Mixed sample' flag is called. Finally, if no serotypes are called due to low coverage $(<90 \%)$ 171 then a 'Failed' flag is called.

172 The capsular types matched in step 1 (genogroup) are fed into step 2 and the relevant 173 information for this specific genogroup is retrieved, if genogroup information is available. This 174 information is organised in a multi-fasta reference file, with complete gene sequences for all 175 genes that display genetic diversity within the selected genogroup, and a database containing all 176 sequence variants pertaining to the same genogroup. Paired reads are then mapped to the loaded 177 reference file using bowtie 2 and the tool tests for the variants loaded from the capsular type 178 variant (CTV) database. Specific functions were designed to detect the different types of 179 variants, such as presence/absence of genes, different alleles, single nucleotide polymorphisms 180 (SNPs) and loss-of-function mutations. Base calling and insertion/deletion detection were made 181 with SAMtools mpileup (version 0.1.19; following options used: -B -A)(Li H., Handsaker B., 182 Wysoker A., Fennell T., Ruan J., Homer N., 2009), requiring a minimum-read depth of 5 and 183 using reads with minimum base mapping quality of 30 . These base calls were only included in 184 the downstream analysis if they constituted $>80 \%$ of read depth (ie, a nonmixed base call). A 185 capsular type is assigned if a 100\% match to all variants tested is achieved, else a 'Failed' flag is 
186 returned. In the case of serogroups 24 and 32, where no distinguishing variants are available, the

187 software returns the serogroup.

\section{Phylogenetic tree generation}

189 Reads were mapped to selected reference sequence using bwa (version 0.7.12)(Li \& Durbin, 190 2009). Variants were called using GATK 2.6.5(McKenna et al., 2010). Variants were then parsed

191 to retain high quality SNPs based on the following conditions: depth of coverage (DP) $\geq 5, A D$ 192 ratio (ratio between variant base and alternative bases) $\geq 0.8$, Mapping Quality (MQ) $\geq 30$, ratio of 193 reads with MQ0 to total number of reads $\leq 0.05$. All positions that fulfilled the filtering criteria 194 in $>0.9$ of the samples were joined to produce a multiple fasta format file where the sequence for 195 each strain consists of the concatenated variants. This file was used as an input to generate a 196 maximum likelihood (ML) tree using RAxML(Stamatakis, 2014) with the following parameters 197 -m (substitutionModel) ASC_GTRCAT --asc_corr=lewis (Paul Lewis's model correction for 198 ascertainment bias when analysing variant-only data) -b (bootstrapRandomNumberSeed) 12345 199 -\# (numberOfRuns) 1000.

200

201 Assembly-based sequence analysis

202 Genomic reads were assembled using SPAdes (version 2.5.1) de novo assembly 203 software(Bankevich et al., 2012) with the following parameters 'spades.py --careful -1 204 strain.1.fastq.gz -2 strain.2.fastq -t 4 -k 21,33,55,77,85,93'. The resulting contigs.fasta file was 205 converted into a BLAST database using blast+(Camacho et al., 2009) (version 2.2.27) and 206 queried using selected query sequence (i.e. gene or capsular operon sequences). 


\section{Results}

\section{Genogroups}

209 Genetic clustering of $S$. pneumoniae strains based on the capsular locus sequence was previously 210 described by Mavroidi et al. (Mavroidi et al., 2007). Based on their analysis, 88 pneumococcal

211 serotypes were grouped in 8 major clusters and 20 subclusters. All but 6 serogroups fell within

212 the same genetic subcluster as previously described(Mavroidi et al., 2007) and 9 of the

213 subclusters contained serotypes from different serogroups. In this study we define genogroups as 214 groups of serotypes with high $(>90 \%)$ sequence identity within the capsular locus. Based on

215 these criteria 21 genogroups were identified by comparing published capsular locus 216 sequences(Bentley et al., 2006). All genogroups contain serotypes grouped within the same 217 genetic subcluster as defined by Mavroidi et al (Mavroidi et al., 2007) (Table 2); 11 of the 218 genogroups correspond to serogroups as defined by the SSI sera, 6 of which also form genetic 219 subclusters described by Mavroidi et al. (Mavroidi et al., 2007). Of the remaining 10 genogroups, 6 are identical to previously described subclusters and 3 correspond to incomplete serogroups. For example, serogroup 10 assigned previously to a single genetic subcluster is split 222 into two genogroups, 10A-10B and 10C-10F. Similarly, serogroup 19 was assigned to a single 223 subcluster, whereas in our analysis only serotypes 19B and 19C form a genogroup. The 224 remaining two serotypes are too genetically dissimilar to be included; 19A shares only $50 \%$ of 225 the capsular locus with 19F, its closest genetic neighbour within the serogroup, whereas 19F 226 shares $65 \%$ with $19 \mathrm{~B}$. The last genogroup is $33 \mathrm{~A}, 33 \mathrm{~F}$ and 37 ; serotypes $33 \mathrm{~A}$ and $33 \mathrm{~F}$ belong to 227 a genetic subcluster; serotype 37 was not included in the previous analysis since it does not use 228 the Wzx/Wzy-dependent pathway. However, previous analysis revealed that serotype 37 isolates 
229 use the $t$ ts synthase gene which is located elsewhere in the genome to define serotype, but still

230 contain a defective 33F-like capsular locus (Llull D., Munoz R., Lopez R., 1999).

\section{Serotype-defining sequence variants}

232 Serotype-defining variants were detected following gene-based alignment of published capsular

233 locus sequences (Bentley et al., 2006). Sequences were extracted in GenBank format and for

234 each genogroup, gene profiling and sequence variant analysis was performed to determine

235 variant profiles that could predict to serotype level. Types of sequence variation investigated

236 include presence/absence of capsular biosynthesis-related genes, detection of inactivating

237 mutations such as early stop codons and frameshifts (insertions, deletions, truncations), detection

238 of differing alleles of genes that can be distinguished by coverage alone due to low sequence

239 similarity $(<80 \%)$ and SNP differences that can be detected by variant calling. Reported variants

240 were then evaluated with our test cohort $(n=871$; Table 2$)$ and variants with $100 \%$ incidence rate

241 (found in all isolates of serotype tested) were incorporated into capsular type variant (CTV)

242 database (Table 3). Many of the variants detected during this study correspond to structural and

243 genetic differences reported previously (Kolkman, van der Zeijst \& Nuijten, 1998; Bentley et al.,

244 2006; Mavroidi et al., 2007; Song, Baek \& Ko, 2011; Yang et al., 2011; Oliver et al., 2013b).

245 In two cases of previously reported frameshift mutations (7A and 15C), the mutations were

246 confirmed in our test cohort, but no consensus of the inactivated sequence was detected (20-80\%

247 of reads carry frameshift mutation). In 7As, an insertion of a thymine (T) at residue 587 of $w c w D$

248 inactivates the glycosyltransferase (Table 3 ) leading to loss of the side branch D-Galp-( $\beta 1-2)-\alpha-$

249 D-Galp(Mavroidi et al., 2007). During evaluation with a cohort of 34 isolates (7A, n=9; 7F,

$250 \mathrm{n}=25-$ Table 2), all 7F isolates carried a wild type (wt) $w c w D$ gene sequence. In comparison, 7/9

251 of the $7 \mathrm{~A}$ isolates also carried a wt $w c w D$ sequence, whereas $2 / 9$ (including the SSI 7A type 
252 strain) exhibited a mixed profile at residue 587, with only a percentage of the reads carrying the

253 insertion (60-70\%). All 7A isolates were retested in the laboratory using the SSI sera and only

254 the two isolates with the mixed profile were re-typed as $7 \mathrm{~A}$ whereas the $7 / 9$ with a wt $w c w D$

255 were typed as 7F, suggesting that this mixed profile is indicative of 7As and can still lead to

256 phenotypic changes. In $15 \mathrm{Cs}$, differences in the length of the TA tandem repeat region of the

257 wciZ gene lead to loss of function for the O-acetyltransferase in 15C and are responsible for the

258 differences in acetylation between 15B and 15C isolates(Bentley et al., 2006). However, unlike

259 the $7 \mathrm{~A} / 7 \mathrm{~F}$ scenario where the two types can be easily distinguished, distinguishing $15 \mathrm{~B}$ and $15 \mathrm{C}$

260 isolates on the bench using SSI sera in the slide agglutination method is extremely challenging.

261 Reversible switching between the 15B and 15C serotypes was previously described in the

262 laboratory and in natural infection(Venkateswaran, Stanton \& Austrian, 1983; Van Selm et al.,

263 2003). Thus, in practice it may not be possible to clearly distinguish between these two serotypes

264 in the laboratory using serological methods and for the reasons above such isolates appear as

$26515 B / C$ in many publications(Laufer et al., 2010). Therefore, it was unsurprising that the capsular

266 typing tool had problems matching the serological results where isolates had previously been

267 reported as either $15 \mathrm{~B}$ or $15 \mathrm{C}$ prior to a change to the reporting; the previous result mostly likely

268 due to the dominance of one type over the other in the mix. During evaluation with 30 isolates

$269(15 \mathrm{~B}, \mathrm{n}=16 ; 15 \mathrm{C} \mathrm{n}=14)$, we encountered $15 \mathrm{~B}$ and mixed $15 \mathrm{~B} / \mathrm{C}$ isolates but no pure $15 \mathrm{C}$ isolates.

270 A genetically pure $15 \mathrm{C}$ was found later during validation but a different frameshift mutation was

271 responsible for the inactivation of wciZ. Overall 11/16 15B isolates were correctly predicted as

$27215 \mathrm{~B}$ and $5 / 16$ were mixed $15 \mathrm{~B} / \mathrm{C}$ whereas $10 / 1415 \mathrm{C}$ isolates were predicted as $15 \mathrm{~B}$ and $4 / 14$ as

$27315 \mathrm{~B} / \mathrm{C}$. Since any 15B-15C-15B/C discordances cannot be resolved in the laboratory the 15B-

$27415 \mathrm{~B} / \mathrm{C}-15 \mathrm{C}$ isolates will always be reported as $15 \mathrm{~B} / \mathrm{C}$. 


\section{Molecular type 6E}

276 Serotype $6 \mathrm{E}$ is not a serologically distinct serotype, , but has been shown to be a distinct

277 molecular subtype(Ko, Baek \& Song, 2013b). Due to the low genetic similarity between the 6E

278 capsular locus sequence and the other serogroup 6 capsular locus sequences, PneumoCaT was

279 unable to determine a serotype for isolates with 6E capsular locus in the first step of the capsular

280 typing tool due to coverage $<90 \%(n=12 ; 106 \mathrm{~B}$ and $26 \mathrm{~A})$. In order to take account of this

281 variation, the genomic sequences of these 12 isolates were used to determine a consensus $6 \mathrm{E}$

282 capsular locus sequence and this was introduced into the capsular locus typing tool. With this in

283 place the tool can determine whether an isolate has a $6 \mathrm{E}$ molecular type and using the variant

284 profiles described above can then determine the serological type (i.e. $6 \mathrm{E}(6 \mathrm{~B})$ ).

\section{Novel serogroup 7 subtype}

286 Genogroup 7B, 7C and 40 can be distinguished using a panel of 9 SNPs (Table S3) all found

287 within glycosyltransferase gene $w c w K$. Nucleotide differences at residues 46 and 385 are

288 considered as more significant, as both result in distinct amino acids in the three serotypes.

289 During evaluation using a cohort of 38 isolates $(7 \mathrm{~B}, \mathrm{n}=15 ; 7 \mathrm{C}, \mathrm{n}=21 ; 40, \mathrm{n}=2$ - Table 1 -

290 Development Set), one isolate originally typed as serotype 7C in the laboratory, exhibited a

291 novel codon at residue 385 which encoded for a distinct amino acid (CTT (Leu) compared to

292 ACT (Thr) for serotype 40, TTT (Phe) for 7B and TGT (Cys) for 7C). The rest of the SNP

293 profile matched the 7B profile. Further investigation revealed a distinct combination of factor

294 sera reactions (Table 4) for this isolate suggesting that it might correspond to a novel serogroup

2957 , serotype. 


\section{Serogroup 22}

297 Biochemical or genetic differences between serotypes 22A and 22F have not been previously 298 described. Initial genetic analysis revealed 99\% identity over $100 \%$ of the capsular locus 299 sequences of the two types (22A: CR931681; 22F: CR931682) suggesting a possible error in 300 submission or serotyping. To investigate this, genomic data from the two SSI type strains (SSI301 22A, SSI-22F) were assembled and using the reference sequence for 22A, the capsular locus 302 sequences were extracted. The extracted sequences were compared to the reference sequences 303 and the capsular locus sequence of SSI-22A was identical to the two reference sequences 304 whereas the SSI-22F had $98 \%$ identity over $91 \%$ of the capsular locus of all three of the other sequences. Specifically, the region covering genes $w c w A$ and $w c w C$ shares no similarity between SSI-22F and 22A. The SSI-22F capsular locus sequence was submitted to ENA as assembly under PHE Pathogens BioProject PRJEB14267 (Accession No LT594600.1).

\section{Novel molecular subtype 23B1}

Serotypes 23A, 23B and 23F have distinct capsular locus sequences which allows for serotype prediction based on mapping coverage alone. A cohort of 72 isolates $(23 \mathrm{~A}, \mathrm{n}=25 ; 23 \mathrm{~B}, \mathrm{n}=25$; $23 \mathrm{~F}, \mathrm{n}=22$ ) was used to test the coverage-based approach. All isolates typed as $23 \mathrm{~A}$ or $23 \mathrm{~F}$ and $21 / 25$ isolates typed as $23 \mathrm{~B}$ were correctly predicted; however $4 \times 23 \mathrm{~B}$ isolates gave a failed result in the capsular typing tool with highest coverage of approximately $70 \%$. These isolates were re-tested in the laboratory using SSI sera and the previous results were confirmed. In order to investigate this further, more $23 \mathrm{~B}$ isolates were sequenced and analysed using the capsular

316 typing tool. In total $24 / 4623 \mathrm{~B}$ isolates failed the pipeline with $70 \%$ coverage. Following further 317 investigation these isolates were identified as a novel molecular subtype (23B1) with $\sim 70 \%$ 
318 homology to the 23B capsular locus (unpublished data). The 23B1 capsular locus sequence was

319 introduced into PneumoCaT assuring 100\% concordance with serological type.

\section{Serogroup 24}

321 Genetic differences between serotypes in serogroup 24 have previously been described(Mavroidi

322 et al., 2007) and were also confirmed following genetic analysis of the reference sequences

323 (Accession no. CR931686-8 for 24A, B and F respectively). Serotype 24A lacks wzy, a

324 polymerase gene and $r b s F$, a putative ribofuranose biosynthetic gene. In addition, the gene

325 sequence of the flippase gene $w z x$ is unique to $24 \mathrm{~A}$ as indicated by using a blast nucleotide query

326 against the NCBI database. This could only be confirmed by the SSI type strain (SSI-24A) since

327 no other 24A isolates were available in the PHE archive. According to Mavroidi et al. serotypes

328 24B and 24F are distinguished by loss of function of genes $a b p l$ and $r m l C$ in 24B(Mavroidi et

329 al., 2007). This was confirmed when comparing the reference sequences. However, following

330 evaluation with a cohort of 25 isolates $(6,24 \mathrm{~B} ; 19,24 \mathrm{~F})$ the frameshift in $r m l C$ was not seen in

331 any of the 24B isolates, including the SSI-24B type strain whereas the frameshift in abpl was

332 only seen in SSI-24B strain, but no other 24B strains. This suggested that either all 24B isolates

333 are actually $24 \mathrm{~F}$ or that the reference sequences are not representative of the circulating strains;

334 the serological typing was repeated for all isolates and original serotypes were confirmed,

335 therefore we surmised that the latter is more likely. Genomic SNP analysis was used to

336 investigate this further by mapping to either (a) the 24F capsular locus sequence (CR931688) or

337 (b) the whole genome of the non-capsular S. pneumoniae R6 strain (NC_003098). Subsequent

338 variant calling and filtering produced 145 and 19123 high quality SNPs, respectively.

339 Evolutionary history was inferred using the Maximum-likelihood method and phylogenetic trees

340 were drawn (Supplementary Figure 1). No serotype specific clustering was observed in either of 
341 the trees suggesting that if there is a molecular basis for the observed serological differences, it

342 occurs using a mechanism that is not vertically inherited e.g rapid strand-slippage variation in a

343 microsatellite within a promoter region. Further investigation is underway but in the meantime,

344 PneumoCaT can predict isolates to serogroup level and serological analysis can distinguish

345 further to serotype level. Although genetic differences have been described above for 346 differentiating $24 \mathrm{~A}$ from $24 \mathrm{~B} / 24 \mathrm{~F}$, they are not currently implemented in PneumoCaT due to 347 incomplete evaluation.

\section{Serogroup 32}

349 Structures for the capsular polysaccharide repeat unit of both serotype 32A and 32F are available and differences based on the structure have previously been described(Bentley et al., 2006; Mavroidi et al., 2007). However, when the two reference capsular locus sequences (32A: CR931696; 32F: CR931697) were aligned, 99\% identity was observed over 99\% of the length of the sequence. The only difference was a $5 \mathrm{bp}$ gap at the intergenic region between $\operatorname{wcr} N$ and the HG272/3 pseudogene observed in the serotype 32 capsular locus. Gene-based analysis returned no nucleotide differences within coding regions. To investigate whether there was a submission error, as described for $22 \mathrm{~F}$, the capsular locus sequences (lacking the tnp regions at the beginning of the capsular locus) of the $32 \mathrm{~A}$ and $32 \mathrm{~F}$ SSI type strains were extracted from the assembled genomes of SSI-32A and SSI-32F strains and compared to the reference strains. Both type sequences showed $100 \%$ identity with the respective reference sequences over the length of the alignment. The serogroup 32 evaluation cohort only includes 5 isolates $(32 \mathrm{~A}, \mathrm{n}=2 ; 32 \mathrm{~F}, \mathrm{n}=3-$ Table 1; Development Set) and following analysis with the capsular typing tool all isolates were assigned to serogroup 32. Further investigation into the BAM files revealed that the 5 bp gap was seen only in the SSI-32F type strain. More serogroup 32 isolates need to be analysed before any 
364 conclusions can be reached, but no serogroup 32 isolates have been observed in the UK since

365 2007. At present the predicted serogroup 32 isolates can only be differentiated into serotypes

366 using serological analyses.

\section{Validation of the capsular typing tool}

368 Following development, the PneumoCaT tool was evaluated using two panels: (a) 2046 UK

369 isolates retrieved from PHE archive covering 72/92 serotypes, including all serotypes contained

370 in commercial vaccines (Table 5; excluding non-typeables) and (b) genomic data from 2964 non-

371 UK isolates from three distinct, publicly available datasets (Thailand; $n=2531$ - 65 serotypes,

372 USA; n=181 - serotype information not available- and Iceland; $n=252$ - serotypes 6A, 6B, 6C

373 and $6 \mathrm{E})$.

374 Both panels were used to evaluate the typability of PneumoCaT based on the proportion of

375 isolates that were assigned a type. In the UK cohort, serotype was assigned initially to $98.2 \%$ of

376 the typeable isolates (2010/2046). Of the 36 failed isolates, 19 were called as mixed and

377 following retesting using a culture from a single colony, 18/19 were resolved, raising the

378 typability to $99.1 \%$. In the non-UK cohort, a serotype was assigned to $99 \%$ of the isolates

$379(2934 / 2964)$ and 8/20 failed ones were called as mixed, suggesting that if retesting was possible

380 these could be resolved.

381 Concordance with currently used methodology (slide agglutination using SSI sera) was evaluated

382 using the UK cohort for which further laboratory testing was possible. Concordance was

383 estimated on the 2028 typeable isolates for which a serotype was called with both methods (2010

$384+18$ mixed resolved). Overall, 92.4\% concordance was observed between the predicted 385 serotypes and the serologically-derived serotypes $(n=1873)$. Discordance was observed in 155 
386 isolates (Table 6) and in most cases $(77 \%, n=119)$, the discordance involved serotypes using the

387 same factor sera set for serotype allocation (i.e. $12 \mathrm{~B} / 12 \mathrm{~F}, 7 \mathrm{~A} / 7 \mathrm{~F}$ discordances) or serotypes

388 using the same pool sera (i.e. serotype 31 and 7F both react with pool C serum)(Statens Serum

389 Institut, 2013) $(\mathrm{n}=22)$. Repeating the serological serotyping for these two sets resolved the initial

390 discordance in $88.7 \%$ of the cases $(125 / 141)$. This suggests that discordance in these cases may

391 be attributed to difficulty in reading slide agglutination reactions during the serological analysis

392 with the SSI sera (i.e. auto-agglutination with all group 12 factor sera in the case of $12 \mathrm{~B} / 12 \mathrm{~F}$

393 typing). In one case a novel serogroup 9 serotype was predicted based on both the SNP-pattern

394 (Table S4) and sera reaction pattern that differed from the expected 9L pattern, showing a weak

395 reaction with factor sera $9 \mathrm{~g}$. In the remaining 14/155 cases, there are no shared sera between the

396 serotypes predicted by WGS and the serologically-derived serotypes. These isolates were

397 retested with both methods and all but one (unable to serotype due to autoagglutination) were

398 concordant suggesting a possible laboratory sample translocation during archiving and/or

399 retrieval of the isolate. Overall, following retesting, we observed a final concordance of $99.3 \%$

400 (2013/2028), with only 18 discordant. In some of these cases serotyping could not resolve the

401 discordance because auto-agglutination leads to inconclusive results $(n=10)$, whereas other cases

$402(n=8)$ exhibit a persistent discordance even after retesting with both methods (Table S9). In these

403 cases, the capsular operon sequence was investigated further using an assembly and blast

404 approach to query for both capsular operons. In all cases, the capsular operon sequence detected

405 did not match the serologically derived serotype. However, it must be noted that for each of these

406 serotypes, serotype was accurately predicted for the majority of cases and these discordant cases

407 are outliers (Table 5). 
408 The serogroup 6 isolates from the Icelandic dataset $(n=252)$ were originally used to demonstrate

409 the distribution of the new 6E type and molecular typing was used to characterized all isolates

410 (van Tonder et al., 2015). Although these isolates were not available for further investigation,

411 they were the only complete dataset with confirmed 6E isolates (molecular confirmation since

412 serological confirmation is not possible), so they were used to demonstrate the ability of

413 PneumoCaT to differentiate 6E from the other serogroup 6 types. Following analysis, 100\%

414 typability and concordance was observed $(n=252)$.

415 Reproducibility of the WGS method was investigated using a subset of 292 UK isolates covering $41682 / 94$ serotypes that were randomly selected for inclusion in the reproducibility study. For this

417 study each isolate was cultured twice and DNA extracted and sequenced at different times.

418 Concordance was seen in all cases.

\section{Non typeable isolates}

420 Virulence of $S$. pneumoniae is classically associated with the capsule, however some pathogenic

421 strains, often associated with non-invasive sites (i.e. respiratory isolates), are serologically non-

422 typeable (NT)(Park et al., 2012). Nineteen NT strains were selected from the PHE archive and 423 analysed using WGS and PneumoCaT to predict serotype. In 13/19 cases PneumoCaT failed to 424 predict serotype with a highest coverage $<50 \%$ (Figure 4 and Table 5 ). This is consistent with 425 lack of a capsular operon and these isolates would be considered non-typeable. In addition, three isolates that originally had been typed in the lab (19A and $2 \times 38)$ but failed with $<50 \%$ coverage

427 during PneumoCaT analysis were retested and found non-typeable in the lab, suggesting that this

428 cut off could be used an indicative of non-typeable isolates following further validation. In the 429 remaining 6/19 cases a serotype was predicted. In three of the cases retesting with SSI sera gave 430 the same serotype as predicted by PneumoCaT. In three other cases repeat serotyping by slide 
431 agglutination consistently failed to give an acceptable result. In all of these cases the colonies

432 had an abnormal morphology (i.e. rough).

\section{Discussion}

434 Molecular capsular typing methods, such as multiplex PCR, have been readily used in reference

435 laboratories across the globe in place of the gold standard Quellung method("WHO | Laboratory

436 methods for the diagnosis of meningitis caused by Neisseria meningitidis, Streptococcus

437 pneumoniae, and Haemophilus influenzae"; European Centre for Diseases Prevention and

438 Control (ECDC), 2013). The lower cost and increased turnaround times associated with such

439 methods have made them the preferred serogrouping/typing method for a number of laboratories.

440 Many conventional and real-time PCR schemes cover the vaccine-related and most commonly

441 observed serotypes(Jauneikaite et al., 2015). However, these methods do not cover all serotypes

442 and many types cannot be distinguished from others with genetically closely related capsular

443 operons. In this study, we present serotype-specific variant profiles that can be used to

444 distinguish 87/92 serologically-distinct serotypes and 2 molecular subtypes, and PneumoCaT, a

445 bioinformatics tool that uses the CTV (Capsular Typing ㅌariant) database to predict capsular 446 type from WGS data.

447 A gene-based approach was used to identify variants that allow differentiation between closely448 related serotypes. During its development stage, a test cohort of 871 clinical isolates, including 449 the SSI-type strains, was used to evaluate the relevance of these variants in the population and 450 establish the CTV database. In many cases, these sequence variants were previously published 451 (e.g. serogroup 6)(Song, Baek \& Ko, 2011), whereas in other cases structural differences have

452 been observed but no molecular information was provided (e.g. serogroup 9). One of the main 453 advantages of this approach is the ability to detect molecular subtypes (and potential new 
454 phenotypes) even if no serological differences are observed using standard typing sera. For

455 example, isolates from serogroups 6 and 23 initially failed the development pipeline due to low

456 capsular locus coverage. Further investigation into the reason for the failures was able to identify

457 serotype 6E, a previously described molecular type(Ko, Baek \& Song, 2013a) and a novel 23B

458 molecular subtype. Another example is serotype 19A, where two subgroups were identified

459 based on the mapping coverage of the 19A capsular locus. In this case, all isolates were still

460 predicted as 19A by PneumoCaT, since more than 90\% coverage was observed for both

461 subgroups, but gene profile analysis revealed variability in the presence of cps $19 \mathrm{aO}$ gene and

462 further functional and epidemiological analysis is currently underway to investigate whether this

463 has any phenotypic relevance. In terms of surveillance, the presence of these new molecular

464 subtypes could indicate introduction of new clones that may influence new pneumococcal

465 vaccine development. In some rare cases, a novel molecular type can also have corresponding

466 serological differences; for example, during the test phase of the variant profiles for genogroup

467 7B-7C-40, an isolate exhibited a distinct codon at position 385 and a distinct factor sera reaction

468 pattern (Table 4) upon retesting in our laboratory. Following further investigation by SSI this

469 isolate has now been confirmed as a novel serotype (authors' unpublished data). In addition,

470 during the validation phase of this study, SNP analysis revealed a novel serogroup 9 type with a

471 distinct sera reaction pattern, but this has not been confirmed.

472 Following the development stage, PneumoCaT was evaluated for typability, accuracy

473 (concordance with serological results) and reproducibility. Typability was evaluated as the

474 percentage of isolates for which a serotype was assigned by PneumoCaT, using two panels of 475 isolates (UK, $n=2046$; non-UK, $n=2964$ ), that combined, cover 82/94 capsular types, including

476 clones that cover 4 different countries (UK, USA, Iceland and Thailand). Using both panels, a 
477 combined typability of 99\% (99.1\% for UK and 99\% for non-UK) was achieved, demonstrating 478 that PneumoCaT can be used to analyse isolates from diverse geographical lineages. The panel 479 of 2028 typeable UK isolates (encompassing 72 serotypes) was then used to evaluate the 480 accuracy of the tool. When discordances between phenotypic serotyping results and PneumoCaT 481 serotype were investigated, the majority (119/155) were shown to be due to problems with 482 determining serotype within serogroup, when using the factor sera in the slide agglutination 483 method. Particular serogroups such as 12, 33 and 35 proved especially problematic (Table 5).

484 This could be due to the way the results are interpreted for the factor sera reactions when used in 485 slide agglutination. For example, in 24/69 Serogroup 12 cases a 12B/12F discordance was observed; 18 serotype 12B isolates were assigned 12F capsular type by PneumoCaT whereas 6 $48712 \mathrm{~F}$ isolates were assigned 12B. Based on the SSI typing scheme a reaction with all three 488 serogroup 12 factor sera $(12 b, 12 c, 12 e)$ is required to identify $12 \mathrm{~B}$, whereas a reaction with factor serum $12 \mathrm{~b}$ only is indicative of $12 \mathrm{~F}$ isolates. Unfortunately, some factor sera agglutination reactions can be weaker than others. Therefore, a weak reaction in all factor sera could be mistaken for auto-agglutination or vice versa, leading to incorrect scoring. In most discordant cases, repeating the phenotypic testing resolved the discordance. In some cases $(n=10)$ a weak reaction or auto-agglutination made interpretation of the serotyping result difficult, thus the serotype could not be confidently called using the slide agglutination method with the standard SSI sera. The standard factor sera obtained from Statens Serum Institut are optimised for use in the Quellung reaction rather than slide agglutination and therefore, it is highly likely that if the 497 serotyping was performed using the gold-standard Quellung method by technicians with the 498 necessary experience, this could resolve the discrepancies in many cases and increase the 499 accuracy of the serotyping. The use of latex absorbed sera specifically designed for agglutination 
500 reactions is also expected to improve the accuracy of the serotyping results for the more difficult

501 to distinguish serotypes. Late in this study a limited number of latex-absorbed subtyping sera

502 were kindly provided by SSI for use in agglutination reactions, and were used to re-serotype all

503 discordant serogroup 12 isolates. The latex sera was able to resolve 22/24 discordances and in

$5042 / 24$ cases a serotype could not be confidently called due to autoagglutination.

505 In addition, some of the observed original discordances clearly came from simple record keeping

506 errors due to the nomenclature of the factor sera being very similar to the nomenclature for the

507 serotypes themselves, such as serotype $15 \mathrm{~A}$ which is reacts with $15 \mathrm{c}$ factor sera, which

508 accounted for several discordant cases where $15 \mathrm{~A}$ isolates had been originally recorded as $15 \mathrm{C}$

509 due to $15 \mathrm{c}$ factor positive result. Similar discordances were also observed in serogroup 6 where

$5106 \mathrm{~A}$ reacts with $6 \mathrm{~b}$ factor sera, $6 \mathrm{~B}$ with $6 \mathrm{c}$ and $6 \mathrm{C}$ with $6 \mathrm{~d}$ factor sera resulting in mis-reporting.

511 This kind of error could be avoided by use of automated reporting mechanisms which take

512 electronically derived results (such as the PneumoCaT output) and enter them directly into

513 laboratory information systems, avoiding manual transcription.

514 Where occasional discordance persisted even after retesting, it involved pairs of serotypes within

515 the same serogroup or with known cross-reactions (Table S9).In these persistent cases, further

516 molecular investigation is underway to determine whether any regions outside of the capsular

517 operon might be involved in this discordance between phenotype and serotype. However, a

518 repeated serotyping error with these particular isolates cannot be excluded since other examples

519 of the same serotypes have concordance between WGS and serology. For example, one of the

520 isolates is serologically 29 where PneumoCaT predicted 35B. The two capsular operon

521 sequences share approximately $70 \%$ of the capsular locus sequence with $87 \%$ similarity and can

522 be distinguished serologically based on the reaction of a single factor sera (i.e. 35a gives positive 
523 reaction if $35 \mathrm{~B}$ and negative if 29 , and there are known cross-reactions between 29 and some of

524 the factor sera for group 35). The presence of a complete serotype 35B capsular operon in this

525 discrepant isolate was confirmed by assembly as well as mapping and following analysis of the

526 capsular locus sequence no differences were found between this isolate and other 35Bs,

527 including two that were originally mistyped as 29 . At this point, further analysis for external

528 factors is underway.

529 Three of the persistent discordances involved serotype 18C;2 assigned 18B and one 18A 530 serotype by PneumoCaT. Following retesting by both WGS and sera; 2 persisted with $18 \mathrm{C} / 18 \mathrm{~B}$ 531 discordance, whereas the third isolate was re-serotyped as $18 \mathrm{~B}$ and retyped as $18 \mathrm{~A}$ by WGS. The $53218 \mathrm{C} / \mathrm{B}$ discordance is not unexpected as both serotypes react with $18 \mathrm{e}$ factor sera whereas $18 \mathrm{c}$ 533 sera reacts only with $18 \mathrm{C}$ serotypes, suggesting that a weak reaction or autoagglutination could

534 lead to false prediction. However, 18B/A discordance is unexpected as the serotypes react with 535 two different factor sera (18d for $18 \mathrm{~A}$ and $18 \mathrm{e}$ for 18B). Interestingly, the molecular difference 536 distinguishing $18 \mathrm{~A}$ and $18 \mathrm{~B}$ is the presence of a non-functional wciX gene in 18B; this difference 537 should have no impact on phenotype, but has successfully differentiated 19 18A/B isolates (18A, $538 \mathrm{n}=11$ and $18 \mathrm{~B}, \mathrm{n}=8)$. We further examined the capsular sequence to determine additional 539 differences that could impact the phenotype. Specifically, we looked into glf gene, which based 540 on previous studies(Bentley et al., 2006) was present as a pseudogene in $18 \mathrm{~B}, 18 \mathrm{C}$, and $18 \mathrm{~F}$. 541 However, when these gene sequences were translated it was evident that a large part of the UDP542 galactopyranase mutase domain was still encoded; specifically within the translated glf sequence 543 in $18 \mathrm{~B}$ and $18 \mathrm{C}$ a 167 amino acid ORF was present and a 204 amino acid ORF in 18F. Both 544 ORFs matched to published UDP-pyranase mutases when compared to the NCBI protein 545 database using BLAST. The genomic reads of the $1918 \mathrm{~A} / \mathrm{B}$ and the discordant $18 \mathrm{~B} / \mathrm{A}$ isolate 
546 were mapped to the 502 nucleotide coding region of $18 \mathrm{~B} g l f$ and as expected $g l f$ was present in

547 all $18 \mathrm{Bs}$ and none of the 18As. However, glf was also found in the 18B/A isolate which also

548 lacks $w c i X$, a genetic marker for 18A. This finding can potentially explain the discordance

549 between phenotype and genotype and incorporation of the glf marker in CTV will prevent any

550 future $18 \mathrm{~A} / \mathrm{B}$ discordances and instead flag them for further investigation.

551 Another of the discordant isolates involved a rare serotype $(41 \mathrm{~A} / 41 \mathrm{~F})$ and was difficult to resolve

552 due to the lack of representative isolates of serogroup 41. If implemented into the routine

553 laboratory, isolates of these rare serotypes would be subjected to traditional serotyping in

554 addition to WGS analysis until the pipeline could be further developed or confidence in the

555 results was assured.

556 The high typability, concordance and reproducibility rates $(99.1,99.2$ and 100\%, respectively)

557 observed with PneumoCaT suggest the method is highly robust and reliable, with less

558 subjectivity than traditional serotyping and full traceability of results. The sensitivity of the

559 method for serotype mixtures is greater than that of the standard method which means that

560 careful preparation and handling of the isolates for DNA extraction and WGS is necessary to

561 avoid cross-contamination, but also means that potentially genuinely mixed serotype cultures can

562 be recognised. For example, an isolate was initially typed as 19A and predicted as mixed 19A/3

563 with WGS when retrieved from the archives for testing. It was found to have colonies with two

564 different morphologies; one very mucoid and growing over a smaller non-mucoid colony form.

565 The mucoid colony was sampled and following retesting serotype 3 was assigned using both

566 traditional serotyping and PneumoCaT. Unfortunately, the smaller colonies could not be sampled

567 in a pure form but were presumably the original serotype 19A, given the PneumoCaT result. 
568 A further advantage of the PneumoCaT method is the extra information obtained in terms of the

569 percentage mapping to the capsular reference and SNPs identified, which could lead to the

570 discovery of novel serotypes. Trends in the mapping percentage (6E and 23B1) and differences

571 in SNP patterns for those entering the CTV detection pathway could be recorded (novel

572 serogroup 7 and serogroup 9 subtypes). These novel types may be missed by standard serotyping

573 methods due to the way the typing sera are cross-absorbed to avoid reactions with known types,

574 this however does not avoid cross-reactions with novel types e.g. 6C which initially cross reacted

575 with 6A serotyping factor sera prior to production of specific factor sera for this type(Lambertsen

$576 \&$ Kerrn, 2010).

577 A small number of isolates $(n=11)$ failed during the first stage (coverage-based) of the capsular

578 typing pipeline and, upon further examination, repeat serotyping was also unable to confidently

579 call a type in 5 cases suggesting that they might be true acapsular, non-typeable isolates. In $2 / 5$

580 cases, \% coverage was between $75-90 \%$ suggesting that a capsular operon was present but not

581 expressed. The remaining 6 isolates fall just short of the $90 \%$ coverage threshold (Figure 4), but

582 the top hit corresponded to the expected serotype/serogroup suggesting that a capsule could still

583 be expressed (Table S10).

584 Non-typeable isolates, lacking a functional capsular operon, also get a 'Failed' tag by 585 PneumoCaT but can easily be distinguished, based on coverage levels, from unusual isolates 586 where serotype prediction failed. Based on our analysis of 19 isolates, serologically non-typeable 587 isolates have a highest coverage value of less than $50 \%$ whereas for unusual isolates whereas 588 some reactions with serotyping sera are seen when the coverage falls within $60-90 \%$. With 589 further data to confirm this observation, a 'Non-typeable' flag could be introduced to 590 PneumoCaT (Figure 4). During our analysis of these non-typeable isolates, in 32\% of the cases a 
591 serotype was predicted by PneumoCaT, indicating a functional operon was present. Upon

592 retesting, half of these gave the serotype predicted and half were still non-typeable, indicating

593 possible external regulatory elements that inhibit expression of the capsule in these organisms.

594 In summary, PneumoCaT is a robust, accurate, sensitive and expandable tool that could 595 revolutionise pneumococcal reference microbiology. This tool has the sensitivity to enable the 596 recognition of mixed serotypes or new subtypes that could be masked by the use of other 597 methods. The flexibility to introduce new types to the CTV database with relative ease means the 598 system can evolve to suit future challenges. The CTV database itself has the potential to inform 599 the further development of other molecular methods, for example PCR or microarray analysis for 600 determination of capsular type and it could be particularly useful for developing non-culture 601 typing schemes. PneumoCaT will enable more detailed surveillance of serotype drift and could 602 be used to target further phenotypic analysis of potential new serotypes. The automated nature of 603 the tool means that it can be incorporated into routine pipelines and results can be populated into 604 laboratory information systems using custom scripts, thus avoiding some of the potential errors 605 associated with manual result recording and entry and suiting a role in reference microbiology.

\section{Acknowledgements}

607 We thank McDonald Prest, Doris Omoigui, Tim Chambers and Maimuna Kimuli for retrieving 608 hundreds of isolates from archives and preparing DNA for sequencing. Cath Arnold and the team 609 in Genome Services and Development Unit, PHE Colindale for sequencing all isolates. Ella 610 Campion, Gurkiran Mankoo and John Duncan for performing routine S. pneumoniae serotyping 611 and repeat testing some isolates. Steve Platt and Tony McNiff for LIMS integration 612 developments. Mark Van der Linden, Anni Virolainen-Julkunen and Siira Lotta for sending the 
613 6D pneumococcus strains. Pernille Landsbo Elverdal, and team (Statens Serum Institut) for 614 preparing and sending latex factor sera.

\section{References}

616 Austrian R. The quellung reaction, a neglected microbiologic technique. The Mount Sinai 617 journal of medicine, New York 43:699-709.

618 Bankevich A., Nurk S., Antipov D., Gurevich AA., Dvorkin M., Kulikov AS., Lesin VM., 619 Nikolenko SI., Pham S., Prjibelski AD., Pyshkin A V., Sirotkin A V., Vyahhi N., Tesler G., 620 Alekseyev MA., Pevzner PA. 2012. SPAdes: a new genome assembly algorithm and its applications to single-cell sequencing. Journal of computational biology : a journal of computational molecular cell biology 19:455-77. DOI: 10.1089/cmb.2012.0021.

623

624

625

626

627

628

629

630

631

632

633

634

Bentley SD., Aanensen DM., Mavroidi A., Saunders D., Rabbinowitsch E., Collins M., Donohoe K., Harris D., Murphy L., Quail MA., Samuel G., Skovsted IC., Kaltoft MS., Barrell B., Reeves PR., Parkhill J., Spratt BG. 2006. Genetic analysis of the capsular biosynthetic locus from all 90 pneumococcal serotypes. PLoS Genetics. DOI: 10.1371/journal.pgen.0020031.

Bolger AM., Lohse M., Usadel B. 2014. Trimmomatic: A flexible trimmer for Illumina sequence data. Bioinformatics. DOI: 10.1093/bioinformatics/btu170.

Brito DA., Ramirez M., Lencastre H De. 2003. Serotyping Streptococcus pneumoniae by Multiplex PCR Serotyping Streptococcus pneumoniae by Multiplex PCR. DOI: 10.1128/JCM.41.6.2378.

Burton RL., Geno KA., Saad JS., Nahm MH. 2016. Pneumococcus with the "6E” cps Locus Produces Serotype 6B Capsular Polysaccharide. Journal of clinical microbiology 54:967- 
635 Calix JJ., Porambo RJ., Brady AM., Larson TR., Yother J., Abeygunwardana C., Nahm MH.

636 2012. Biochemical, genetic, and serological characterization of two capsule subtypes among

637 Streptococcus pneumoniae serotype 20 strains: Discovery of a new pneumococcal serotype.

638 Journal of Biological Chemistry. DOI: 10.1074/jbc.M112.380451.

639 Calix JJ., Nahm MH. 2010. A new pneumococcal serotype, 11E, has a variably inactivated wcjE 640 gene. The Journal of infectious diseases. DOI: 10.1086/653123.

641 Camacho C., Coulouris G., Avagyan V., Ma N., Papadopoulos J., Bealer K., Madden TL. 2009.

642 BLAST+: architecture and applications. BMC bioinformatics. DOI: 10.1186/1471-2105-10$643 \quad 421$.

644 Centers for Disease Control and Prevention (CDC). 2010. Licensure of a 13-valent 645 pneumococcal conjugate vaccine (PCV13) and recommendations for use among children 646 Advisory Committee on Immunization Practices (ACIP), 2010. MMWR. Morbidity and 647 mortality weekly report 59:258-61.

648 Chewapreecha C., Harris SR., Croucher NJ., Turner C., Marttinen P., Cheng L., Pessia A., 649 Aanensen DM., Mather AE., Page AJ., Salter SJ., Harris D., Nosten F., Goldblatt D., 650 Corander J., Parkhill J., Turner P., Bentley SD. 2014. Dense genomic sampling identifies 651 highways of pneumococcal recombination. Nature genetics 46:305-9. DOI:

652 10.1038/ng.2895.

653 Croucher NJ., Harris SR., Fraser C., Quail MA., Burton J., van der Linden M., McGee L., von 654 Gottberg A., Song JH., Ko KS., Pichon B., Baker S., Parry CM., Lambertsen LM., Shahinas 655 D., Pillai DR., Mitchell TJ., Dougan G., Tomasz A., Klugman KP., Parkhill J., Hanage WP., 656 Bentley SD. 2011. Rapid pneumococcal evolution in response to clinical interventions. 657 Science (New York, N.Y.). DOI: 10.1126/science.1198545. 
658 Dallman TJ., Chattaway MA., Cowley LA., Doumith M., Tewolde R., Wooldridge DJ.,

659 Underwood A., Ready D., Wain J., Foster K., Grant KA., Jenkins C. 2014. An investigation

660 of the diversity of strains of enteroaggregative escherichia coli isolated from cases

661 associated with a large multi-pathogen foodborne outbreak in the UK. PLoS ONE. DOI:

$662 \quad$ 10.1371/journal.pone.0098103.

663 European Centre for Diseases Prevention and Control (ECDC). 2013. European Centre for

664 Disease Prevention and Control. Surveillance of invasive bacterial diseases in Europe,

665 2011. DOI: $10.2900 / 1510$.

666 Everett DB., Cornick J., Denis B., Chewapreecha C., Croucher N., Harris S., Parkhill J., Gordon

667 S., Carrol ED., French N., Heyderman RS., Bentley SD. 2012. Genetic Characterisation of

668 Malawian Pneumococci Prior to the Roll-Out of the PCV13 Vaccine Using a High-

669 Throughput Whole Genome Sequencing Approach. PLoS ONE. DOI:

$670 \quad$ 10.1371/journal.pone.0044250.

671 Habib M., Porter BD., Satzke C. 2014. Capsular Serotyping of Streptococcus pneumoniae Using

672 the Quellung Reaction Video Link. J. Vis. Exp 84:512083791-51208. DOI: 10.3791/51208.

673 Jauneikaite E., Tocheva AS., Jefferies JM., Gladstone RA., Faust SN., Christodoulides M.,

674 Hibberd ML., Clarke SC. 2015. Current methods for capsular typing of Streptococcus

675 pneumoniae. Journal of Microbiological Methods:41-9. DOI:

$676 \quad$ 10.1016/j.mimet.2015.03.006.

677 Jolley KA., Maiden MCJ. 2010. BIGSdb: Scalable analysis of bacterial genome variation at the 678 population level. BMC bioinformatics 11:595. DOI: 10.1186/1471-2105-11-595.

679 Ko KS., Baek JY., Song JH. 2013a. Capsular gene sequences and genotypes of "serotype 6E" 
680

681

682

683

684

685

686

687

688

689

690

691

692

693

694

695

696

697

698

699

700

701

streptococcus pneumoniae isolates. Journal of Clinical Microbiology. DOI: 10.1128/JCM.01645-13.

Ko KS., Baek JY., Song JH. 2013b. Capsular gene sequences and genotypes of "serotype 6E" streptococcus pneumoniae isolates. Journal of Clinical Microbiology. DOI: 10.1128/JCM.01645-13.

Kolkman MA., van der Zeijst BA., Nuijten PJ. 1998. Diversity of capsular polysaccharide synthesis gene clusters in Streptococcus pneumoniae. Journal of biochemistry 123:937-45.

Kronvall G. 1973. A RAPID SLIDE-AGGLUTINATION METHOD FOR TYP ING PNEUMOCOCCI BY MEANS OF SPECIFIC ANTIBODY ADSORBED TO PROTEIN A-CONTAINING STAPHYLOCOCCI. Journal of Medical Microbiology:187-190.

Lambertsen L., Kerrn MB. 2010. Test of a novel Streptococcus pneumoniae serotype 6C type specific polyclonal antiserum (factor antiserum 6d) and characterisation of serotype 6C isolates in Denmark. BMC infectious diseases 10:282. DOI: 10.1186/1471-2334-10-282.

Langmead B. and Salzberg S. 2012. Fast gapped-read alignment with Bowtie 2. Nature Methods 9:357-9.

Laufer AS., Thomas JC., Figueira M., Gent JF., Pelton SI., Pettigrew MM. 2010. Capacity of serotype 19A and 15B/C Streptococcus pneumoniae isolates for experimental otitis media: Implications for the conjugate vaccine. Vaccine 28:2450-7. DOI: 10.1016/j.vaccine.2009.12.078.

Li H., Durbin R. 2009. Fast and accurate short read alignment with Burrows-Wheeler transform. Bioinformatics (Oxford, England) 25:1754-60. DOI: 10.1093/bioinformatics/btp324.

Li H., Handsaker B., Wysoker A., Fennell T., Ruan J., Homer N. et al. 2009. The sequence 
alignment/map format and SAMtools. Bioinformatics. Bioinformatics 25:2078-9.

703

704

705

706

707

708

709

710

711

712

Liyanapathirana V., Ang I., Tsang D., Fung K., Ng TK., Zhou H., Ip M. 2014. Application of a target enrichment-based next-generation sequencing protocol for identification and sequence-based prediction of pneumococcal serotypes. BMC microbiology 14:60. DOI: $10.1186 / 1471-2180-14-60$.

Llull D., Munoz R., Lopez R. GE. 1999. A Single Gene (tts) located outside the cap Locus directs the formation of Streptococcus pneumoniae type 37 capsular polysaccharide. . Journal of Experimental Medicine 190:241-251.

Magomani V., Wolter N., Tempia S., Du Plessis M., De Gouveia L., Von Gottberg A. 2014. Challenges of Using Molecular Serotyping for Surveillance of Pneumococcal Disease. Journal of clinical microbiology 52:3271-3276. DOI: 10.1128/JCM.01061-14.

Mavroidi A., Aanensen DM., Godoy D., Skovsted IC., Kaltoft MS., Reeves PR., Bentley SD., Spratt BG. 2007. Genetic relatedness of the Streptococcus pneumoniae capsular biosynthetic loci. Journal of Bacteriology. DOI: 10.1128/JB.00836-07.

McKenna A., Hanna M., Banks E., Sivachenko A., Cibulskis K., Kernytsky A., Garimella K., Altshuler D., Gabriel S., Daly M., DePristo MA. 2010. The Genome Analysis Toolkit: a MapReduce framework for analyzing next-generation DNA sequencing data. Genome research 20:1297-303. DOI: 10.1101/gr.107524.110.

Metcalf BJ., Gertz RE., Gladstone RA., Walker H., Sherwood LK., Jackson D., Li Z., Law C., Hawkins PA., Chochua S., Sheth M., Rayamajhi N., Bentley SD., Kim L., Whitney CG., McGee L., Beall B., Active Bacterial Core surveillance team. 2016. Strain features and distributions in pneumococci from children with invasive disease before and after 13-valent 
724

725

726

727

728

729

730

731

732

733

734

735

736

737

738

739

740

741

742

743

744

745

conjugate vaccine implementation in the USA. Clinical microbiology and infection: the official publication of the European Society of Clinical Microbiology and Infectious Diseases 22:60.e9-60.e29. DOI: 10.1016/j.cmi.2015.08.027.

Miller E., Andrews NJ., Waight PA., Slack MP., George RC. 2011. Herd immunity and serotype replacement 4 years after seven-valent pneumococcal conjugate vaccination in England and Wales: an observational cohort study. The Lancet. Infectious diseases 11:760-8. DOI: 10.1016/S1473-3099(11)70090-1.

Oliver MB., Van Der Linden MPG., Küntzel SA., Saad JS., Nahm MH. 2013a. Discovery of streptococcus pneumoniae serotype 6 variants with glycosyltransferases synthesizing two differing repeating units. Journal of Biological Chemistry. DOI: 10.1074/jbc.M113.480152.

Oliver MB., Jones C., Larson TR., Calix JJ., Zartler ER., Yother J., Nahm MH. 2013 b.

Streptococcus pneumoniae serotype 11D has a bispecific glycosyltransferase and expresses two different capsular polysaccharide repeating units. The Journal of biological chemistry 288:21945-54. DOI: 10.1074/jbc.M113.488528.

Park IH., Kim K-H., Andrade AL., Briles DE., McDaniel LS., Nahm MH. 2012. Nontypeable pneumococci can be divided into multiple cps types, including one type expressing the novel gene pspK. mBio 3. DOI: 10.1128/mBio.00035-12.

Park IH., Geno KA., Yu J., Oliver MB., Kim K-H., Nahm MH. 2015. Genetic, Biochemical, and Serological Characterization of a New Pneumococcal Serotype, 6H, and Generation of a Pneumococcal Strain Producing Three Different Capsular Repeat Units. Clinical and Vaccine Immunology. DOI: 10.1128/CVI.00647-14.

Porter BD., Ortika BD., Satzke C. 2014. Capsular Serotyping of Streptococcus pneumoniae by 
Latex Agglutination Video Link. J. Vis. Exp. DOI: 10.3791/51747.

747

748

749

750

751

752

753

754

755

756

757

758

759

760

761

762

763

764

765

766

767

Regev-Yochay G., Paran Y., Bishara J., Oren I., Chowers M., Tziba Y., Istomin V., Weinberger M., Miron D., Temper V. RG and DR. 2015. Early impact of PCV7/PCV13 sequential introduction to the national pediatric immunization plan,on adult invasive pneumococcal disease:A nationwide surveillance study. Vaccine:1135-42.

Richter SS., Heilmann KP., Dohrn CL., Riahi F., Diekema DJ., Doern G V. 2013. Evaluation of pneumococcal serotyping by multiplex PCR and quellung reactions. Journal of Clinical Microbiology. DOI: 10.1128/JCM.01876-13.

Van Selm S., Van Cann LM., Kolkman MAB., Van der Zeijst BAM., Van Putten JPM. 2003. Genetic Basis for the Structural Difference between Streptococcus pneumoniae Serotype 15B and 15C Capsular Polysaccharides. Infection and Immunity. DOI:

10.1128/IAI.71.11.6192-6198.2003.

Song JH., Baek JY., Ko KS. 2011. Comparison of capsular genes of Streptococcus pneumoniae Serotype 6A, 6B, 6C, and 6D isolates. Journal of Clinical Microbiology. DOI: 10.1128/JCM.02628-10.

Stamatakis A. 2014. RAxML version 8: a tool for phylogenetic analysis and post-analysis of large phylogenies. Bioinformatics (Oxford, England) 30:1312-3. DOI: 10.1093/bioinformatics/btu033.

Statens Serum Institut. 2013. Streptococcus pneumoniae: Textbook in Diagnosis, Serotyping, Virulence Factors and Enzyme-linked Immunosorbent Assay (ELISA) for Measuring Pneumococcal Antibodies.

Tamura K., Stecher G., Peterson D., Filipski A., Kumar S. 2013. MEGA6: Molecular 
evolutionary genetics analysis version 6.0. Molecular Biology and Evolution. DOI: 10.1093/molbev/mst197.

770

771

772

773

774

775

776

777

778

779

780

781

782

783

784

785

786

787

788

789

Thompson JD., Higgins DG., Gibson TJ. 1994. CLUSTAL W: improving the sensitivity of progressive multiple sequence alignment through sequence weighting, position-specific gap penalties and weight matrix choice. Nucleic acids research 22:4673-80.

van Tonder AJ., Bray JE., Roalfe L., White R., Zancolli M., Quirk SJ., Haraldsson G., Jolley KA., Maiden MCJ., Bentley SD., Haraldsson Á., Erlendsdóttir H., Kristinsson KG., Goldblatt D., Brueggemann AB. 2015. Genomics Reveals the Worldwide Distribution of Multidrug-Resistant Serotype 6E Pneumococci. Journal of clinical microbiology 53:227185. DOI: 10.1128/JCM.00744-15.

Turner P., Hinds J., Turner C., Jankhot A., Gould K., Bentley SD., Nosten F., Goldblatt D. 2011. Improved detection of nasopharyngeal cocolonization by multiple pneumococcal serotypes by use of latex agglutination or molecular serotyping by microarray. Journal of Clinical Microbiology. DOI: 10.1128/JCM.00157-11.

Venkateswaran PS., Stanton N., Austrian R. 1983. Type Variation of Strains of Streptococcus pneumoniae in Capsular Serogroup 15. Journal of Infectious Diseases 147:1041-1054. DOI: 10.1093/infdis/147.6.1041.

Waight PA., Andrews NJ., Ladhani SN., Sheppard CL., Slack MPE., Miller E. 2015. Eff ect of the 13 -valent pneumococcal conjugate vaccine on invasive pneumococcal disease in England and Wales 4 years after its introduction: an observational cohort study. Articles Lancet Infect Dis 15:535-43.

WHO | Laboratory methods for the diagnosis of meningitis caused by Neisseria meningitidis, 
790 Streptococcus pneumoniae, and Haemophilus influenzae

791 Yang J., Nahm MH., Bush CA., Cisar JO. 2011. Comparative structural and molecular

792 characterization of Streptococcus pneumoniae capsular polysaccharide serogroup 10. The

793 Journal of biological chemistry 286:35813-22. DOI: 10.1074/jbc.M111.255422.

794

795

796

797 
Figure 1

Serotype distribution of UK pneumococcal isolates

Number of IPD isolates referred to PHE per epidemiological year (July 2011 to June 2015).

Serotypes with less than 10 isolates in all periods were removed.

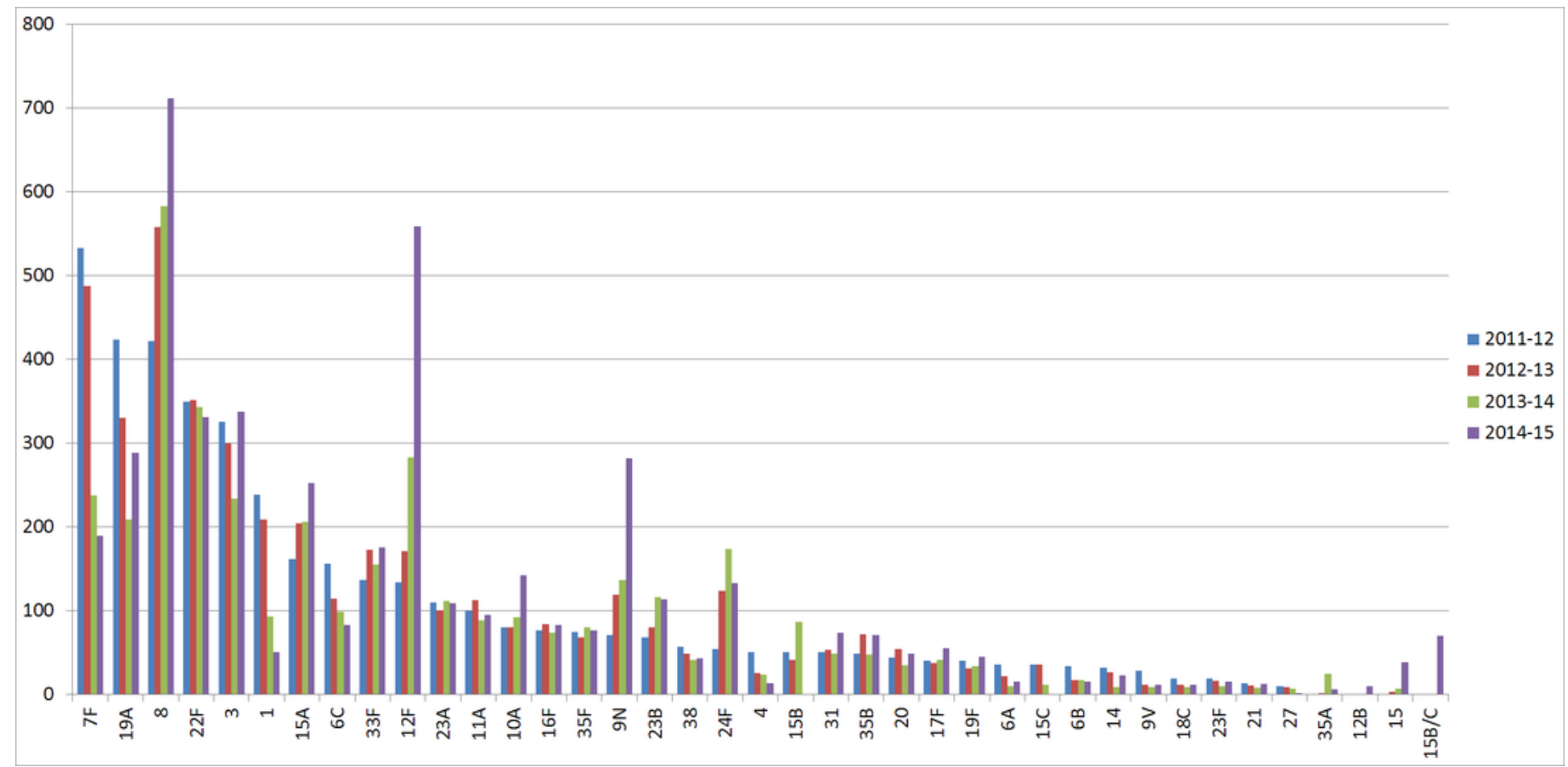


Figure 2

PneumoCaT process workflow

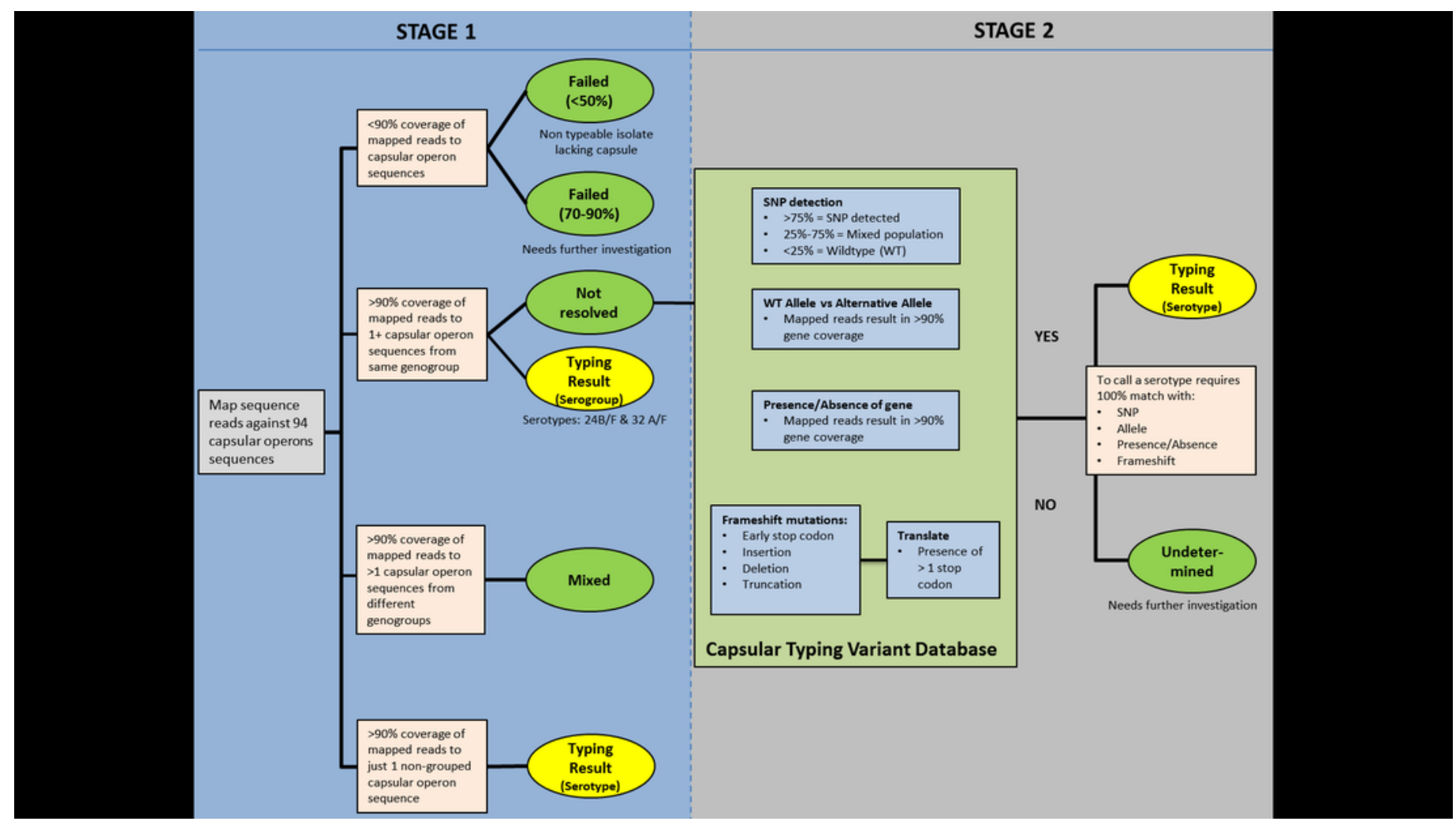


Figure 3

Average \% coverage of the top and second hit during stage 1 of the PneumoCaT for serotypes determined by mapping coverage only.

Error bars correspond to standard deviation.

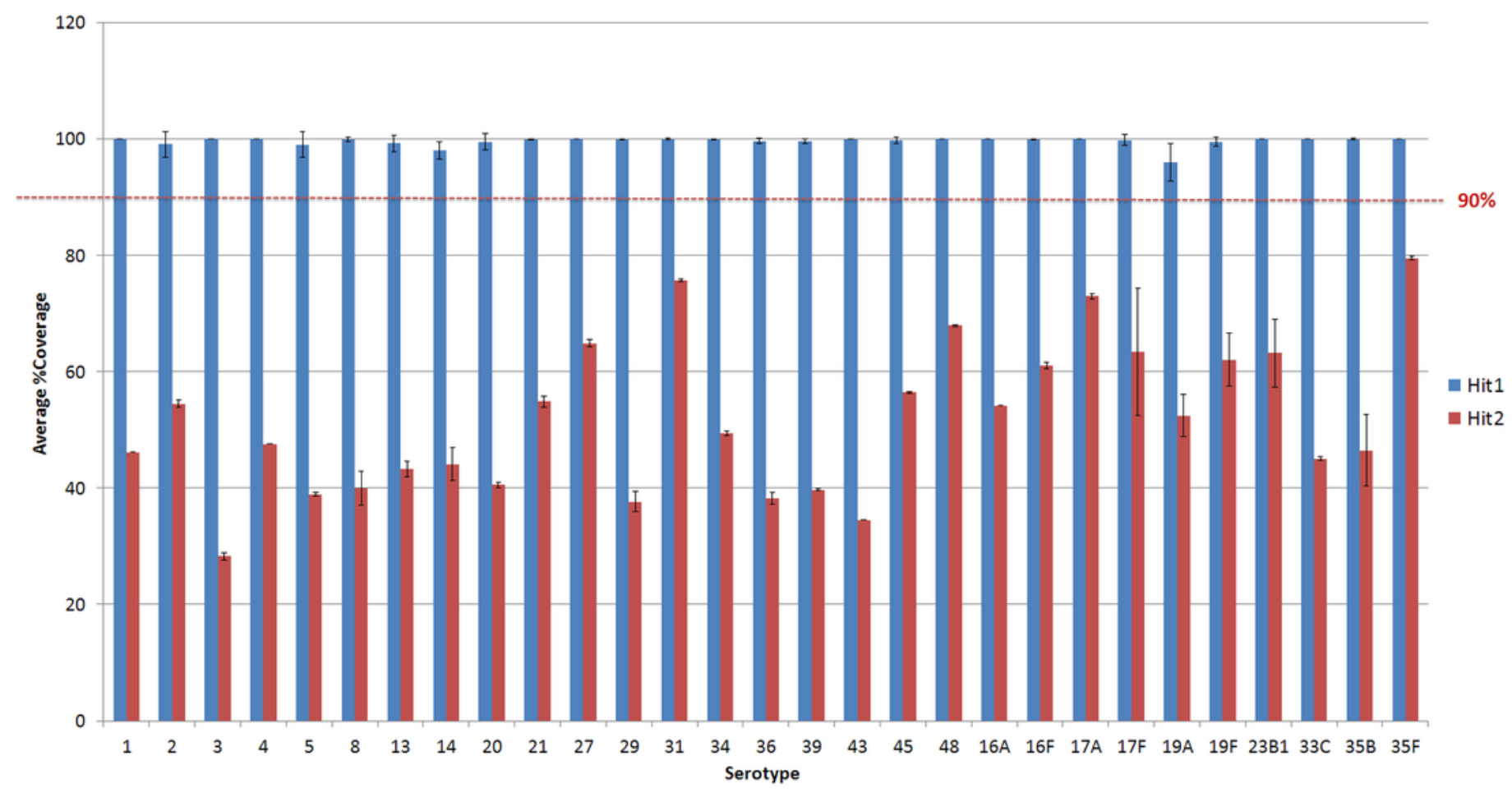


Figure 4

Percent coverage distribution of top serotype hit in PneumoCaT stage 1 for all $S$. pneumoniae isolates $(n=2065)$ in the study.

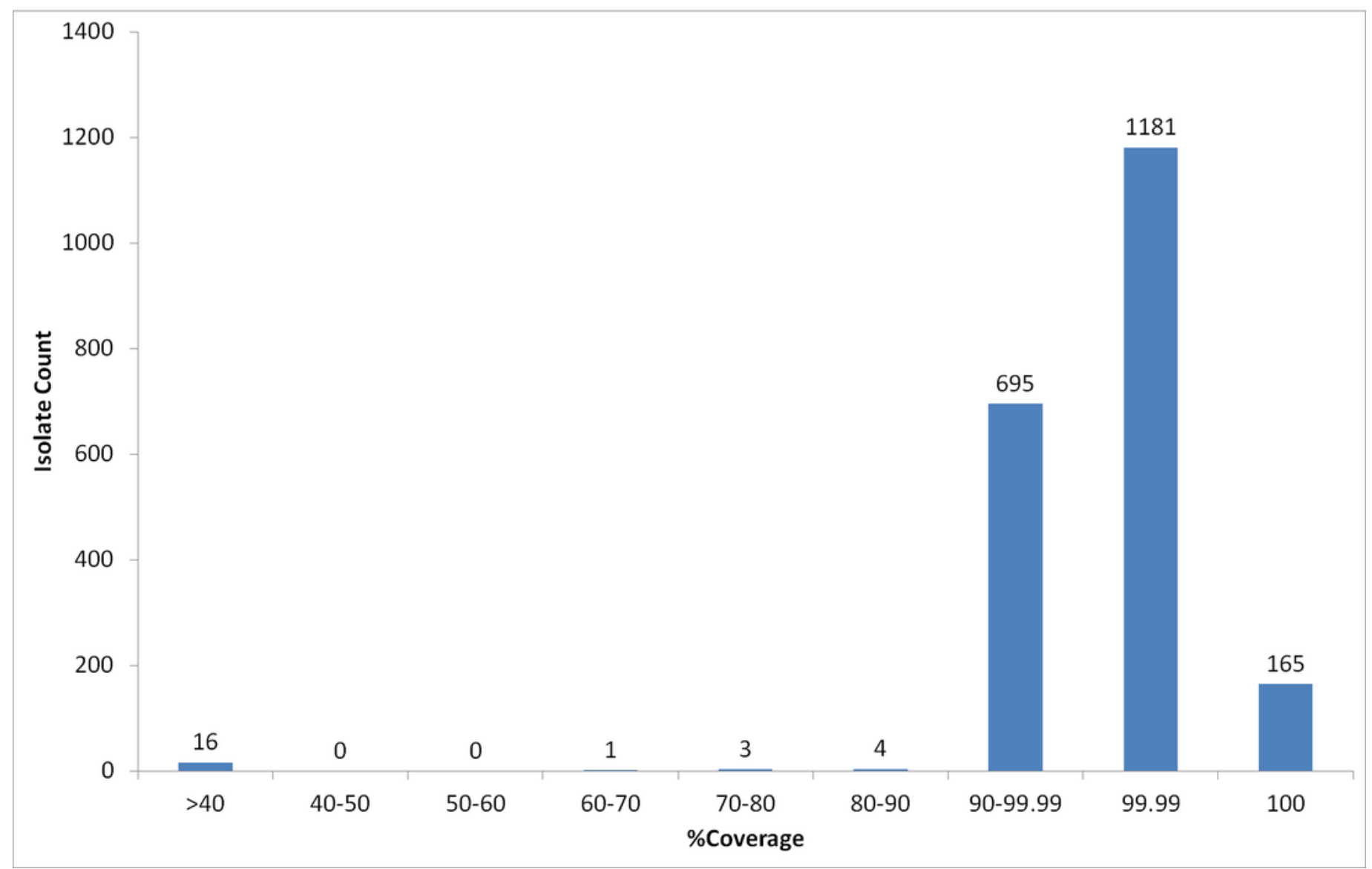




\section{Table 1 (on next page)}

Number of isolates from each serotype included in this study. 


\begin{tabular}{|c|c|c|c|}
\hline Serotype & $\begin{array}{c}\text { Development } \\
\text { Set }\end{array}$ & $\begin{array}{c}\text { Validation } \\
\text { Set }\end{array}$ & Total \\
\hline 1 & 4 & 41 & 45 \\
\hline 2 & 3 & 9 & 12 \\
\hline 3 & 5 & 44 & 49 \\
\hline 4 & 3 & 43 & 46 \\
\hline 5 & 3 & 41 & 44 \\
\hline 8 & 7 & 70 & 77 \\
\hline 13 & 3 & 20 & 23 \\
\hline 14 & 5 & 43 & 48 \\
\hline 20 & 3 & 42 & 45 \\
\hline 21 & 3 & 21 & 24 \\
\hline 27 & 5 & 23 & 28 \\
\hline 29 & 2 & 21 & 23 \\
\hline 31 & 8 & 22 & 30 \\
\hline 34 & 3 & 22 & 25 \\
\hline 36 & 2 & 5 & 7 \\
\hline 37 & 8 & 22 & 30 \\
\hline 38 & 16 & 23 & 39 \\
\hline 39 & 2 & 2 & 4 \\
\hline 40 & 2 & & 2 \\
\hline 42 & 2 & & 2 \\
\hline 43 & 1 & & 1 \\
\hline 44 & 1 & & 1 \\
\hline 45 & 2 & & 2 \\
\hline 46 & 6 & & 6 \\
\hline 48 & 2 & 5 & 7 \\
\hline $06 \mathrm{~A}$ & 22 & 41 & 63 \\
\hline 06B & 23 & 43 & 66 \\
\hline $06 C$ & 25 & 22 & 47 \\
\hline 06D & 5 & 2 & 7 \\
\hline 07A & 2 & 5 & 7 \\
\hline 07B & 15 & 4 & 19 \\
\hline 07C & 21 & 24 & 45 \\
\hline $07 F$ & 32 & 40 & 72 \\
\hline 09A & 8 & 6 & 14 \\
\hline 09L & 9 & 2 & 11 \\
\hline $09 N$ & 17 & 44 & 61 \\
\hline 09V & 33 & 45 & 78 \\
\hline $10 \mathrm{~A}$ & 13 & 44 & 57 \\
\hline $10 \mathrm{~B}$ & 2 & 7 & 9 \\
\hline $10 \mathrm{C}$ & 1 & & 1 \\
\hline $10 \mathrm{~F}$ & 24 & 22 & 46 \\
\hline $11 \mathrm{~A}$ & 38 & 44 & 82 \\
\hline $11 \mathrm{~B}$ & 6 & 2 & 8 \\
\hline
\end{tabular}




\begin{tabular}{|c|c|c|c|}
\hline & & \multirow[b]{2}{*}{4} & \multirow[b]{2}{*}{6} \\
\hline $11 C$ & 2 & & \\
\hline 11D & 1 & & 1 \\
\hline $11 \mathrm{~F}$ & 1 & & 1 \\
\hline $12 \mathrm{~A}$ & 4 & 2 & 6 \\
\hline $12 B$ & 5 & 24 & 29 \\
\hline $12 \mathrm{~F}$ & 28 & 44 & 72 \\
\hline $15 \mathrm{~A}$ & 18 & 196 & 214 \\
\hline $15 B$ & 17 & 41 & 58 \\
\hline $15 B / C$ & & 8 & 8 \\
\hline $15 \mathrm{C}$ & 14 & 24 & 38 \\
\hline $15 \mathrm{~F}$ & 2 & 2 & 4 \\
\hline $16 \mathrm{~A}$ & 1 & & 1 \\
\hline $16 \mathrm{~F}$ & 15 & 21 & 36 \\
\hline $17 \mathrm{~A}$ & 3 & & 3 \\
\hline $17 F$ & 15 & 41 & 56 \\
\hline $18 \mathrm{~A}$ & 4 & 11 & 15 \\
\hline $18 \mathrm{~B}$ & 4 & 9 & 13 \\
\hline $18 \mathrm{C}$ & 5 & 41 & 46 \\
\hline $18 \mathrm{~F}$ & 2 & 5 & 7 \\
\hline $19 A$ & 28 & 249 & 277 \\
\hline $19 B$ & 1 & 1 & 2 \\
\hline $19 C$ & 1 & 1 & 2 \\
\hline $19 \mathrm{~F}$ & 18 & 41 & 59 \\
\hline $22 \mathrm{~A}$ & 9 & 2 & 11 \\
\hline $22 \mathrm{~F}$ & 31 & 43 & 74 \\
\hline $23 \mathrm{~A}$ & 26 & 23 & 49 \\
\hline $23 B$ & 45 & 79 & 124 \\
\hline $23 \mathrm{~F}$ & 22 & 41 & 63 \\
\hline $24 \mathrm{~A}$ & 1 & 2 & 3 \\
\hline $24 B$ & 6 & & 6 \\
\hline $24 \mathrm{~F}$ & 19 & & 19 \\
\hline \multicolumn{4}{|c|}{ Serogroup } \\
\hline 24 & & 31 & 31 \\
\hline $25 \mathrm{~A}$ & 3 & 1 & 4 \\
\hline $25 \mathrm{~F}$ & 10 & 1 & 11 \\
\hline $28 \mathrm{~A}$ & 15 & 19 & 34 \\
\hline $28 \mathrm{~F}$ & 4 & 1 & 5 \\
\hline $32 \mathrm{~A}$ & 2 & & 2 \\
\hline $32 \mathrm{~F}$ & 3 & & 3 \\
\hline $33 \mathrm{~A}$ & 3 & 5 & 8 \\
\hline $33 B$ & 4 & 1 & 5 \\
\hline $33 C$ & 2 & 1 & 3 \\
\hline $33 D$ & 1 & & 1 \\
\hline $33 \mathrm{~F}$ & 19 & 43 & 62 \\
\hline $35 \mathrm{~A}$ & 9 & 24 & 33 \\
\hline
\end{tabular}




\begin{tabular}{l|c|cc}
$35 \mathrm{~B}$ & 29 & 23 & 52 \\
$35 \mathrm{C}$ & 2 & 4 & 6 \\
$35 \mathrm{~F}$ & 13 & 22 & 35 \\
$41 \mathrm{~A}$ & 3 & 1 & 4 \\
$41 \mathrm{~F}$ & 2 & & 2 \\
$47 \mathrm{~A}$ & 1 & & 1 \\
$47 \mathrm{~F}$ & 1 & & 1 \\
NT & & 19 & 19 \\
\hline Grand Total & $\mathbf{8 7 1}$ & $\mathbf{2 0 6 7}$ & $\mathbf{2 9 3 8}$ \\
\hline
\end{tabular}

1 


\section{Table 2 (on next page)}

Comparison of genogroups defined in this study and genetic subclusters defined by Mavroidi et al. 


\begin{tabular}{|l|l|}
\hline Genogroups & Genetic subclusters \\
\hline $6 \mathrm{~A}, 6 \mathrm{~B}, 6 \mathrm{C}, 6 \mathrm{D}, 6 \mathrm{E}$ & $6 \mathrm{~A}, 6 \mathrm{~B}$ \\
\hline $7 \mathrm{~A}, 7 \mathrm{~F}$ & $7 \mathrm{~A}, 7 \mathrm{~F}$ \\
\hline $7 \mathrm{~B}, 7 \mathrm{C}, 40$ & $7 \mathrm{~B}, 7 \mathrm{C}, 40$ \\
\hline $9 \mathrm{~A}, 9 \mathrm{~L}, 9 \mathrm{~V}, 9 \mathrm{~N}$ & $9 \mathrm{~A}, 9 \mathrm{~L}, 9 \mathrm{~V}, 9 \mathrm{~N}$ \\
\hline $10 \mathrm{~A}, 10 \mathrm{~B}$ & $10 \mathrm{~A}, 10 \mathrm{~B}, 10 \mathrm{C}, 10 \mathrm{~F}$ \\
\hline $10 \mathrm{C}, 10 \mathrm{~F}$ & \\
\hline $11 \mathrm{~A}, 11 \mathrm{~B}, 11 \mathrm{C}, 11 \mathrm{D}, 11 \mathrm{~F}$ & $11 \mathrm{~A}, 11 \mathrm{~B}, 11 \mathrm{C}, 11 \mathrm{D}, 11 \mathrm{~F}$ \\
\hline $12 \mathrm{~A}, 12 \mathrm{~B}, 12 \mathrm{~F}, 44,46$ & $12 \mathrm{~A}, 12 \mathrm{~B}, 12 \mathrm{~F}, 44,46$ \\
\hline $15 \mathrm{~A}, 15 \mathrm{~B}, 15 \mathrm{C}, 15 \mathrm{~F}$ & $15 \mathrm{~A}, 15 \mathrm{~B}, 15 \mathrm{C}, 15 \mathrm{~F}$ \\
\hline $18 \mathrm{~A}, 18 \mathrm{~B}, 18 \mathrm{C}, 18 \mathrm{~F}$ & $18 \mathrm{~A}, 18 \mathrm{~B}, 18 \mathrm{C}, 18 \mathrm{~F}$ \\
\hline $19 \mathrm{~B}, 19 \mathrm{C}$ & $19 \mathrm{~A}, 19 \mathrm{~B}, 19 \mathrm{C}, 19 \mathrm{~F}$ \\
\hline $22 \mathrm{~A}, 22 \mathrm{~F}$ & $22 \mathrm{~A}, 22 \mathrm{~F}$ \\
\hline $23 \mathrm{~A}, 23 \mathrm{~B}, 23 \mathrm{~F}$ & $23 \mathrm{~A}, 23 \mathrm{~B}, 23 \mathrm{~F}$ \\
\hline $24 \mathrm{~A}, 24 \mathrm{~B}, 24 \mathrm{~F}$ & $24 \mathrm{~A}, 24 \mathrm{~B}, 24 \mathrm{~F}, 17 \mathrm{~F}, 48$ \\
\hline $25 \mathrm{~A}, 25 \mathrm{~F}, 38$ & $25 \mathrm{~A}, 25 \mathrm{~F}, 38$ \\
\hline $28 \mathrm{~A}, 28 \mathrm{~F}$ & $28 \mathrm{~A}, 28 \mathrm{~F}, 16 \mathrm{~F}$ \\
\hline $32 \mathrm{~A}, 32 \mathrm{~F}$ & $32 \mathrm{~A}, 32 \mathrm{~F}, 27$ \\
\hline $33 \mathrm{~A}, 33 \mathrm{~F}, 37$ & $33 \mathrm{~A}, 33 \mathrm{~F}$ \\
\hline $33 \mathrm{~B}, 33 \mathrm{D}$ & $33 \mathrm{~B}, 33 \mathrm{D}$ \\
\hline $35 \mathrm{~A}, 35 \mathrm{C}, 42$ & $35 \mathrm{~A}, 35 \mathrm{C}, 42$ \\
\hline $41 \mathrm{~A}, 41 \mathrm{~F}$ & $41 \mathrm{~A}, 41 \mathrm{~F}, 17 \mathrm{~A}, 31$ \\
\hline & \\
\hline
\end{tabular}

1 


\section{Table 3 (on next page)}

Table 3: Genetic differentiation of serotypes within serogroups.

Description of variants present in the CTV database. 


\begin{tabular}{|c|c|c|c|}
\hline Serogroup & Serotype & $\begin{array}{l}\text { Distinguishing genetic } \\
\text { features }\end{array}$ & Functional Effect \\
\hline \multirow[b]{2}{*}{6} & $6 \mathrm{~A} / 6 \mathrm{~B}$ and $6 \mathrm{C} / 6 \mathrm{D}$ & $A>G 583$ in wciP & $\begin{array}{l}\text { amino acid substitution (Ser195Asn) which results to different rhamnose- } \\
\text { ribitol linkages ( } 1 \rightarrow 3 \text { in 6A/6C and } 1 \rightarrow \text { in 6B/6D)(Mavroidi et al., 2007; } \\
\text { Sheppard et al., 2010; Baek et al., 2014) }\end{array}$ \\
\hline & $\begin{array}{l}6 \mathrm{~A} / 6 \mathrm{C} \text { and } 6 \mathrm{~B} / 6 \mathrm{D} \text { and } \\
6 \mathrm{E}\end{array}$ & $\begin{array}{l}\text { wciN } \alpha \text { in } 6 \mathrm{~A} \text { and } 6 \mathrm{~B} / \\
\text { wciN6in } 6 \mathrm{C} \text { and } 6 \mathrm{~B} / \\
\text { wciNy in } 6 \mathrm{E}\end{array}$ & $\begin{array}{l}\text { Allele wciN } \alpha \text { encodes for galactosyl-transferase whereas wciNB is } 200 \mathrm{bp} \\
\text { shorter and encodes for a glycosyl-transferase - consistent with changes } \\
\text { in structure(Park et al., 2007). WciNy is a chimeric form of wciN } \alpha \text { (75\%) } \\
\text { and wciNB (25\%). }\end{array}$ \\
\hline \multirow{2}{*}{$\begin{array}{l}7 \text { and } \\
\text { serotype } \\
40\end{array}$} & $7 \mathrm{~A} / 7 \mathrm{~F}$ & $\begin{array}{l}\text { Frameshift mutation insT } 587 \\
\text { in } 7 A \text { WcWD gene }\end{array}$ & $\begin{array}{l}\text { Loss of function of glycosyltransferase leading to loss of side branch for } \\
\text { 7A(Mavroidi et al., 2007). } \\
{ }^{*} \text { "Mixed: ['07A','07F']” result corresponds to 7A phenotype (see Results). }\end{array}$ \\
\hline & 7B/7C/40 & SNPs in wcwK (Table S1) & $\begin{array}{l}\text { Amino acid changes - } w c w K \text { encodes for a GT but } 7 C \text { and } 40 \text { structure not } \\
\text { known }\end{array}$ \\
\hline \multirow{3}{*}{9} & $9 \mathrm{~A} / 9 \mathrm{~V}$ & $\begin{array}{l}\text { Frameshift mutation delG } \\
722 \text { in } 9 A \text { wcjE }\end{array}$ & Loss of function of O-acetyltranferase leads to differences in acetylation \\
\hline & 9L/9N & $\begin{array}{l}\text { SNPs in genes wchA, wcjA, } \\
\text { wcjB and wzy (Table S2) }\end{array}$ & $\begin{array}{l}\text { Amino acid changes - wcjA and wcjB encode for glycosyltranferases (GT) } \\
\text { and changes in these are consistent with presence of glucose in } 9 \mathrm{~N} \\
\text { instead of galactose present in residue } 3 \text { of the polysaccharide repeat } \\
\text { unit of the other three serotypes(Mavroidi et al., 2007) }\end{array}$ \\
\hline & $9 A / 9 V / 9 L / 9 N$ & $\begin{array}{l}\text { presence of an additional O- } \\
\text { acetyltransferase encoded by } \\
w c j D \text { in } 9 A-9 \mathrm{~V}\end{array}$ & Differences in acetylation \\
\hline 10 & $10 \mathrm{~A} / 10 \mathrm{~B} / 10 \mathrm{C} / 10 \mathrm{~F}$ & $\begin{array}{l}10 \mathrm{~A} / 10 \mathrm{~B} \text { carries gene } w c r G \\
\text { whereas } 10 \mathrm{C} / 10 \mathrm{~F} \text { carries } \\
\text { genes } w c r H \text { and } w c i G\end{array}$ & $\begin{array}{l}\text { wcrH encodes for GT and is responsible for side branch linkage } \\
\text { Galf( } 1-6) \text { Galp present in } 10 \mathrm{~F} \text { but not in } 10 \mathrm{~A} \text {; wcrG encodes for GT and it } \\
\text { catalyzes the linkage of Galp( 1-6) side branch in 10A(Aanensen et al., } \\
\text { 2007) }\end{array}$ \\
\hline
\end{tabular}




\begin{tabular}{|c|c|c|c|}
\hline & $10 \mathrm{~A} / 10 \mathrm{~B} / 10 \mathrm{C} / 10 \mathrm{~F}$ & $\begin{array}{l}10 \mathrm{~A} / 10 \mathrm{C} \text { have } \text { wcrC } \alpha \\
\text { whereas } 10 \mathrm{~B} / 10 \mathrm{~F} \text { have } \\
\text { wcrCB }\end{array}$ & $\begin{array}{l}\text { wcrCB allele is described as } w c r F \text { and both genes encode for } \\
\text { glucosyltransferases and are responsible for the differences observed in } \\
\text { the linkage between galactose and ribitol-5-phosphate(Yang et al., 2011) }\end{array}$ \\
\hline \multirow{3}{*}{11} & $11 \mathrm{~A} / 11 \mathrm{~B} / 11 \mathrm{C} / 11 \mathrm{D} / 11 \mathrm{~F}$ & $\begin{array}{l}\text { genes } w c w C \text { and } w c j E \text { are } \\
\text { present in } 11 \mathrm{~A}, 11 \mathrm{D} \text { and } 11 \mathrm{~F} \\
\text { whereas gene } w c w R \text { is } \\
\text { present in } 11 \mathrm{~B} \text { and } \\
11 C \text { (Mavroidi et al., 2007) }\end{array}$ & $\begin{array}{l}w c w C, w c j E \text { and } w c w R \text { are acetyltransferase genes - differences in } \\
\text { acetylation }\end{array}$ \\
\hline & $11 \mathrm{~A} / 11 \mathrm{~B} / 11 \mathrm{C} / 11 \mathrm{D} / 11 \mathrm{~F}$ & $\begin{array}{l}\text { Frameshift mutation delA } \\
130 \text { in gct in } 11 \mathrm{~B} \text { and } 11 \mathrm{~F}\end{array}$ & $\begin{array}{l}\text { presence of Gro-1P correlates with an intact gct gene in types } \\
11 \mathrm{~A} \text { and } 11 \mathrm{C} \text {; gct is frameshifted in types } 11 \mathrm{~F} \text { and } 11 \mathrm{~B} \text {, and } \\
\text { Rib-ol is present in the CPS instead of Gro(Mavroidi et al., 2007) }\end{array}$ \\
\hline & $11 \mathrm{~A} / 11 \mathrm{D} / 11 \mathrm{~F}$ & $\begin{array}{l}\text { wcrL pos 334: codon AAT } \\
\text { (Asn) in 11A; codon ACT (Ser) } \\
\text { in } 11 \mathrm{D} \text { (Oliver et al., 2013) } \\
\text { and codon GCT (Ala) in 11F }\end{array}$ & $\begin{array}{l}\text { wcrL encodes for a GT - donor sugar for WcrL is GlcpNAc in types } 11 \mathrm{~F} \text {, } \\
11 \mathrm{~B} \text {, and } 11 \mathrm{C} \text { but Glcp in type } 11 \mathrm{~A} \text { (Mavroidi et al., 2007) }\end{array}$ \\
\hline $\begin{array}{l}12 \text { and } \\
\text { serotypes } \\
44 \text { and } 46\end{array}$ & $12 \mathrm{~A} / 12 \mathrm{~B} / 12 \mathrm{~F} / 44 / 46$ & $\begin{array}{l}\text { SNPs in genes } w c x D \text { and } w c x F \\
\text { (Table S3) }\end{array}$ & $\begin{array}{l}\text { Both genes encode for GTs present only in this genogroup(Mavroidi et } \\
\text { al., 2007)- effect on sugar chain unknown (no structure for 12B, } 44 \text { and } \\
\text { 46) }\end{array}$ \\
\hline 15 & $15 \mathrm{~A} / 15 \mathrm{~B} / 15 \mathrm{C} / 15 \mathrm{~F}$ & $\begin{array}{l}\text { 15F has } 4 \text { additional genes; } \\
\text { glf, rm/B, rmID and } \\
\text { wcjE(Bentley et al., 2006) }\end{array}$ & $\begin{array}{l}g l f, r m I B \text { and } r m I D \text { are involved in sugar biosynthesis; wcjE encodes for } \\
\text { an acetyltraferase. }\end{array}$ \\
\hline
\end{tabular}




\begin{tabular}{|c|c|c|c|}
\hline & $15 \mathrm{~A} / 15 \mathrm{~B} / 15 \mathrm{C}$ & $\begin{array}{c}15 A \text { wch L has } 81 \% \text { identity in } \\
\text { the first } 300 \text { bps compare to } \\
\text { the allele found in } 15 \mathrm{~B} / 15 \mathrm{C} \text {, } \\
\text { whereas } 15 \mathrm{~A} \text { wzd has } 69 \% \\
\text { identity in the last } 300 \mathrm{bps} \\
\text { when compared to the } 15 \mathrm{~B} / \mathrm{C} \\
\text { allele }\end{array}$ & $\begin{array}{l}\text { wchL encodes for a GT; wzd is involved in translocation of mature CPS to } \\
\text { the cell surface and thus is responsible for determining the length of the } \\
\text { capsule polysaccharide chain(Bentley et al., 2006) }\end{array}$ \\
\hline & $15 B / 15 C$ & $\begin{array}{l}\text { difference in TA tandem } \\
\text { repeat region near position } \\
413 \text { of wciZ, leading to } \\
\text { frameshift in } 15 C \text { (Bentley et } \\
\text { al., 2006) }\end{array}$ & $\begin{array}{l}\text { wciZ encodes for an O-acetyltransferase - differences in acetylation. } \\
{ }^{*} 15 \mathrm{~B}, 15 \mathrm{~B} / \mathrm{C} \text { and } 15 \mathrm{C} \text { results can be assigned (see Results section) }\end{array}$ \\
\hline 16 & $16 \mathrm{~A}, 16 \mathrm{~F}$ & mapping only & \\
\hline 17 & $17 \mathrm{~A}, 17 \mathrm{~F}$ & mapping only & \\
\hline \multirow[t]{2}{*}{18} & $18 \mathrm{~A} / 18 \mathrm{~B} / 18 \mathrm{C} / 18 \mathrm{~F}$ & $\begin{array}{l}\text { 18F has an extra } \\
\text { acetyltransferase gene } \\
\text { (wcxM) and type 18A lacks } \\
\text { the acetyltransferase gene } \\
\text { wciX(Mavroidi et al., 2007) }\end{array}$ & Differences in acetylation \\
\hline & $18 \mathrm{~B} / 18 \mathrm{C}$ & $\begin{array}{l}\text { G>T } 168 \text { in wciX leads to } \\
\text { early stop codon in } \\
\text { 18B(Mavroidi et al., 2007) }\end{array}$ & wciX encodes for an acetylotranferase - difference in acetylation \\
\hline \multirow[b]{2}{*}{19} & $19 \mathrm{~A}, 19 \mathrm{~F}$ & mapping only & \\
\hline & $19 B / 19 C$ & $\begin{array}{l}\text { 19B lacks genes wchU, } \\
\text { HG264 and glf }\end{array}$ & $\begin{array}{l}\text { wchU encodes for a putative GT and could be responsible for the } \\
\text { additional glucose in the capsular polysaccharide repeat unit of } 19 \mathrm{C} \text {; glf } \\
\text { encodes for a UDP-galactopyranose mutase whereas HG264 has no } \\
\text { functional product }\end{array}$ \\
\hline
\end{tabular}




\begin{tabular}{|c|c|c|c|}
\hline 22 & $22 \mathrm{~A} / 22 \mathrm{~F}$ & $\begin{array}{l}\text { WCWA and } w C W C \text { share no } \\
\text { similarity between } 22 \mathrm{~A} \text { and } \\
22 \mathrm{~F} \text {. }\end{array}$ & $\begin{array}{l}w c w A \text {, encoding for a putative glycosyl-transferase and } w c w C \text {, encoding } \\
\text { for a putative O-acetyltranferase - structure for } 22 \mathrm{~A} \text { unknown }\end{array}$ \\
\hline \multirow[t]{2}{*}{23} & $23 \mathrm{~A} / 23 \mathrm{~B} / 23 \mathrm{~F}$ & $\begin{array}{l}\text { distinct wzy sequence in all } \\
\text { serotypes }\end{array}$ & $\begin{array}{l}\text { wzy encodes for a polymerase and differences in sequence should } \\
\text { account for the different polymerization linkages(Mavroidi et al., 2007) - } \\
\text { structures for 23A and 23B unknown }\end{array}$ \\
\hline & $23 \mathrm{~A} / 23 \mathrm{~B} / 23 \mathrm{~F}$ & $\begin{array}{l}\text { wchA is identical in } 23 \mathrm{~B} \text { and } \\
23 \mathrm{~F} \text { but distinct in } 23 \mathrm{~A} .\end{array}$ & $\begin{array}{l}\text { wchA encodes for a glycosyl-1-phosphatase transferase(Aanensen et al., } \\
2007) \text { - structures for 23A and 23B unknown }\end{array}$ \\
\hline \multirow{3}{*}{$\begin{array}{l}25 \text { and } \\
\text { serotype } \\
\quad 38\end{array}$} & $25 \mathrm{~A} / 25 \mathrm{~F} / 38$ & $\begin{array}{l}\text { wcy } V \text { missing in } 38 \text { (Mavroidi } \\
\text { et al., 2007) }\end{array}$ & \multirow{3}{*}{$\begin{array}{c}\text { wcyV, wcyD and wcyC encode for GTs(Aanensen et al., 2007) - no } \\
\text { structures available for } 25 \mathrm{~A}, 25 \mathrm{~F} \text { or } 38\end{array}$} \\
\hline & $25 \mathrm{~A} / 25 \mathrm{~F} / 38$ & $\begin{array}{l}\text { wcyD } \alpha \text { in serogroup } 25 \text { and } \\
w c y D B \text { in serotype } 38\end{array}$ & \\
\hline & $25 \mathrm{~A} / 25 \mathrm{~F} / 38$ & SNPs in wcyC (Table S4) & \\
\hline 28 & $28 \mathrm{~A} / 28 \mathrm{~F}$ & SNPs in wciU (Table S5) & wciU encodes for a GT - no structures available \\
\hline \multirow{4}{*}{$\begin{array}{l}33 \text { and } \\
\text { serotype } \\
\quad 37\end{array}$} & $33 \mathrm{~A} / 33 \mathrm{~F} / 37$ & $\begin{array}{l}37 \text { carries } t \text { ts - a transferase } \\
\text { gene }\end{array}$ & $\begin{array}{l}\text { tts is responsible for the polysaccharide capsule synthesis in } 37 \text { (Waite et } \\
\text { al., 2003) }\end{array}$ \\
\hline & $33 \mathrm{~A} / 33 \mathrm{~F}$ & $\begin{array}{l}\text { Frameshift mutation insT } 433 \\
\text { in } 33 \mathrm{~F} \text { wcjE gene }\end{array}$ & $\begin{array}{l}\text { Loss of function of O-acetyltranferase leads to differences in } \\
\text { acetylation(Mavroidi et al., 2007) }\end{array}$ \\
\hline & $33 B / 33 D$ & $w c i N \alpha$ in $33 B$ / wciNBin $33 C$ & $\begin{array}{l}\text { wciN } \alpha \text { encodes for a putative glycosyltranferase whereas wciN } \alpha \\
\text { encodes for a putative galactosyltransferase - consistent with } \\
\text { differences in structure }\end{array}$ \\
\hline & $33 C$ & mapping only & \\
\hline \multirow{3}{*}{$\begin{array}{l}35 \text { and } \\
\text { serotype } \\
\quad 42\end{array}$} & $35 \mathrm{~B}, 35 \mathrm{~F}$ & mapping only & \\
\hline & $35 \mathrm{~A} / 35 \mathrm{C} / 42$ & $\begin{array}{l}\text { SNPs in genes mnp1, wcrl } \\
\text { and } w z h \text { (Table S6) }\end{array}$ & $\begin{array}{l}\text { mnp1 encodes for a putative nucleotidyltranferase (NDP-mannitol } \\
\text { pathway), wcrL, a GT and } w z h \text {, a protein-tyrosine phosphatase - } \\
\text { consistent with differences in structure }\end{array}$ \\
\hline & $35 \mathrm{~A} / 35 \mathrm{C} / 42$ & $\begin{array}{l}\text { Frameshift mutation insA } \\
248 \text { in 35A wcrK(Mavroidi et } \\
\text { al., 2007) }\end{array}$ & wcrk encodes for a GT - consistent with differences in structure \\
\hline
\end{tabular}




\begin{tabular}{|l|l|l|l|}
\hline 41 & $41 \mathrm{~A} / 41 \mathrm{~F}$ & $\begin{array}{l}\text { Frameshift mutation delG 23 } \\
\text { in 41A wcrX(Mavroidi et al., } \\
2007)\end{array}$ & wcrX encodes for a acetyltranferase - differences in acetylation \\
\hline 47 & $47 \mathrm{~A}, 47 \mathrm{~F}$ & mapping only & \\
\hline
\end{tabular}

2 References:

3 Aanensen DM., Mavroidi A., Bentley SD., Reeves PR., Spratt BG. 2007. Predicted functions and linkage specificities of the products of the

4 Streptococcus pneumoniae capsular biosynthetic loci. Journal of Bacteriology. DOI: 10.1128/JB.00837-07.

5 Baek JY., Park IH., Song JH., Ko KS. 2014. Prevalence of isolates of Streptococcus pneumoniae putative serotype 6E in South Korea. Journal of 6 Clinical Microbiology. DOI: 10.1128/JCM.00228-14.

7 Bentley SD., Aanensen DM., Mavroidi A., Saunders D., Rabbinowitsch E., Collins M., Donohoe K., Harris D., Murphy L., Quail MA., Samuel G.,

8 Skovsted IC., Kaltoft MS., Barrell B., Reeves PR., Parkhill J., Spratt BG. 2006. Genetic analysis of the capsular biosynthetic locus from all 90 9 pneumococcal serotypes. PLoS Genetics. DOI: 10.1371/journal.pgen.0020031.

10 Mavroidi A., Aanensen DM., Godoy D., Skovsted IC., Kaltoft MS., Reeves PR., Bentley SD., Spratt BG. 2007. Genetic relatedness of the

11 Streptococcus pneumoniae capsular biosynthetic loci. Journal of Bacteriology. DOI: 10.1128/JB.00836-07.

12 Oliver MB., Jones C., Larson TR., Calix JJ., Zartler ER., Yother J., Nahm MH. 2013. Streptococcus pneumoniae serotype 11D has a bispecific

13 glycosyltransferase and expresses two different capsular polysaccharide repeating units. The Journal of biological chemistry 288:21945-54.

14 DOI: $10.1074 / j b c . M 113.488528$. 
Park IH., Pritchard DG., Cartee R., Brandao A., Brandileone MCC., Nahm MH. 2007. Discovery of a new capsular serotype (6C) within serogroup 6 of Streptococcus pneumoniae. Journal of clinical microbiology 45:1225-33. DOI: 10.1128/JCM.02199-06.

17 Sheppard CL., Pichon B., George RC., Hall LMC. 2010. Streptococcus pneumoniae isolates expressing a capsule with epitopes of both serotypes 6A and 6B. Clinical and Vaccine Immunology. DOI: 10.1128/CVI.00335-10.

Waite RD., Penfold DW., Struthers JK., Dowson CG. 2003. Spontaneous sequence duplications within capsule genes cap8E and tts control phase variation in Streptococcus pneumoniae serotypes 8 and 37. Microbiology (Reading, England) 149:497-504. DOI: 10.1099/mic.0.26011-0. polysaccharide serogroup 10. The Journal of biological chemistry 286:35813-22. DOI: 10.1074/jbc.M111.255422. 


\section{Table 4(on next page)}

Factor serum reactions for novel serogroup 7 serotype compared to other types within the group. 


\begin{tabular}{|c|c|c|c|c|}
\cline { 2 - 5 } \multicolumn{1}{c|}{} & 7b & 7c & 7e & 7f \\
\hline 7F & + & - & - & - \\
\hline 7A & (+) & + & - & - \\
\hline 7B & - & - & + & - \\
\hline 7C & - & - & - & + \\
\hline novel & - & - & + & + \\
\hline
\end{tabular}

1 


\section{Table 5 (on next page)}

Detail breakdown of the concordance analysis for the UK validation panel $(n=2065$; 2046 typeable and 19 non-typeables).

* - if not possible to resolve discordance using serology a 15B/C serotype is reported

$¥$ - Novel 9 serotype by WGS and SSI sera 


\begin{tabular}{|c|c|c|c|c|c|c|c|}
\hline \multirow[b]{2}{*}{ Serotype } & \multirow[b]{2}{*}{ Total } & \multicolumn{3}{|c|}{ INITIAL } & \multicolumn{3}{|c|}{ AFTER RETESTING } \\
\hline & & $\begin{array}{c}\text { Concordan } \\
t\end{array}$ & $\begin{array}{c}\text { Discordan } \\
t\end{array}$ & $\begin{array}{c}\text { Failed } \\
\text { WGS }\end{array}$ & $\begin{array}{c}\text { Concordan } \\
t\end{array}$ & $\begin{array}{c}\text { Discordan } \\
t\end{array}$ & $\begin{array}{c}\text { Non- } \\
\text { typeable }\end{array}$ \\
\hline 1 & 41 & 40 & 1 & & 40 & & \\
\hline 2 & 9 & 8 & 1 & & 8 & & \\
\hline 3 & 44 & 44 & & & 46 & & \\
\hline 4 & 43 & 43 & & & 44 & & \\
\hline 5 & 41 & 40 & 1 & & 40 & & \\
\hline 8 & 70 & 70 & & & 72 & & \\
\hline 13 & 20 & 20 & & & 20 & & \\
\hline 14 & 43 & 40 & 3 & & 40 & 1 & \\
\hline 20 & 42 & 39 & 3 & & 40 & & \\
\hline 21 & 21 & 21 & & & 21 & & \\
\hline 27 & 23 & 23 & & & 24 & & \\
\hline 29 & 21 & 9 & 11 & 1 & 9 & 1 & 1 \\
\hline 31 & 22 & 22 & & & 23 & & \\
\hline 34 & 22 & 22 & & & 24 & & \\
\hline 36 & 5 & 3 & 1 & 1 & 3 & & \\
\hline 37 & 22 & 21 & 1 & & 22 & & \\
\hline 38 & 23 & 19 & 1 & 3 & 19 & & 1 \\
\hline 39 & 2 & 2 & & & 2 & & \\
\hline 40 & & & & & 1 & & \\
\hline 42 & & & & & & & \\
\hline 43 & & & & & & & \\
\hline 44 & & & & & & & \\
\hline 45 & & & & & & & \\
\hline 46 & & & & & & & \\
\hline 48 & 5 & 5 & & & 5 & & \\
\hline $06 \mathrm{~A}$ & 41 & 41 & & & 42 & & \\
\hline 06B & 43 & 37 & 6 & & 37 & & \\
\hline $06 C$ & 22 & 21 & 1 & & 24 & & \\
\hline $06 \mathrm{D}$ & 2 & 1 & 1 & & 2 & & \\
\hline $07 \mathrm{~A}$ & 5 & 1 & 4 & & 1 & & \\
\hline 07B & 4 & 3 & 1 & & 3 & & \\
\hline 07C & 24 & 22 & 2 & & 22 & & \\
\hline $07 \mathrm{~F}$ & 40 & 38 & 2 & & 43 & & \\
\hline 09A & 6 & 1 & 5 & & 1 & & 1 \\
\hline 09L & 2 & 1 & 1 & & 1 & & \\
\hline $09 \mathrm{~N}$ & 44 & 42 & 2 & & 43 & & \\
\hline $09 \mathrm{~V}$ & 45 & 45 & & & 49 & & \\
\hline $10 \mathrm{~A}$ & 44 & 41 & 3 & & 42 & 1 & \\
\hline $10 \mathrm{~B}$ & 7 & 6 & 1 & & 6 & & \\
\hline $10 \mathrm{C}$ & & & & & & & \\
\hline $10 \mathrm{~F}$ & 22 & 19 & 1 & 2 & 20 & & \\
\hline $11 \mathrm{~A}$ & 44 & 40 & 2 & 2 & 46 & & \\
\hline
\end{tabular}




\begin{tabular}{|c|c|c|c|c|c|c|c|}
\hline $11 B$ & 2 & 2 & & & 2 & & \\
\hline $11 \mathrm{C}$ & 4 & & 4 & & & & \\
\hline 11D & & & & & & & \\
\hline $11 \mathrm{~F}$ & & & & & & & \\
\hline $12 \mathrm{~A}$ & 2 & & 1 & 1 & & & \\
\hline $12 B$ & 23 & 5 & 18 & & 9 & & \\
\hline $12 \mathrm{~F}$ & 44 & 38 & 6 & & 58 & & 2 \\
\hline $15 \mathrm{~A}$ & 196 & 191 & 4 & 1 & 200 & & \\
\hline $15 B^{*}$ & 41 & 40 & & 1 & 42 & & \\
\hline $15 B / C^{*}$ & 8 & 8 & & & 26 & & \\
\hline $15 C^{*}$ & 24 & 16 & 6 & 2 & 1 & & \\
\hline $15 \mathrm{~F}$ & 2 & & 2 & & & & \\
\hline $16 \mathrm{~A}$ & & & & & & & \\
\hline $16 \mathrm{~F}$ & 21 & 21 & & & 25 & & \\
\hline $17 \mathrm{~A}$ & & & & & & & \\
\hline $17 \mathrm{~F}$ & 41 & 41 & & & 42 & & \\
\hline $18 \mathrm{~A}$ & 11 & 11 & & & 11 & & \\
\hline $18 \mathrm{~B}$ & 9 & 8 & 1 & & 8 & & \\
\hline $18 \mathrm{C}$ & 41 & 38 & 3 & & 39 & 3 & \\
\hline $18 \mathrm{~F}$ & 5 & 3 & 2 & & 3 & & \\
\hline $19 A$ & 249 & 245 & 3 & 1 & 246 & & \\
\hline $19 B$ & 1 & 1 & & & 1 & & \\
\hline $19 \mathrm{C}$ & 1 & & 1 & & & & \\
\hline $19 \mathrm{~F}$ & 41 & 41 & & & 42 & & \\
\hline $22 \mathrm{~A}$ & 2 & 2 & & & 2 & & \\
\hline $22 \mathrm{~F}$ & 43 & 43 & & & 47 & & \\
\hline $23 \mathrm{~A}$ & 23 & 22 & 1 & & 25 & & \\
\hline $23 B$ & 79 & 78 & 1 & & 90 & & \\
\hline $23 \mathrm{~F}$ & 40 & 27 & 11 & 2 & 27 & & \\
\hline $24 \mathrm{~A}$ & 2 & & 2 & & & & \\
\hline Serogroup 24 & 31 & 30 & 1 & & 34 & & \\
\hline $25 \mathrm{~A}$ & 1 & & 1 & & & & 1 \\
\hline $25 \mathrm{~F}$ & 1 & 1 & & & 1 & & \\
\hline $28 \mathrm{~A}$ & 19 & 19 & & & 19 & & \\
\hline $28 \mathrm{~F}$ & 1 & & 1 & & & & \\
\hline Serogroup 32 & & & & & & & \\
\hline $33 A$ & 5 & & 5 & & & & 2 \\
\hline $33 B$ & 1 & 1 & & & 1 & & \\
\hline $33 C$ & 1 & & & 1 & & & \\
\hline $33 D$ & & & & & & & \\
\hline $33 \mathrm{~F}$ & 43 & 43 & & & 48 & & \\
\hline $35 \mathrm{~A}$ & 24 & 4 & 20 & & 4 & & 1 \\
\hline $35 B$ & 23 & 23 & & & 52 & & \\
\hline $35 \mathrm{C}$ & 4 & & 4 & & & 1 & 1 \\
\hline $35 \mathrm{~F}$ & 22 & 21 & 1 & & 22 & & \\
\hline
\end{tabular}




\begin{tabular}{|c|c|c|c|c|c|c|c|}
\hline $\begin{array}{r}41 \mathrm{~A} \\
41 \mathrm{~F} \\
47 \mathrm{~A} \\
47 \mathrm{~F} \\
\text { NOVEL } 9 \neq\end{array}$ & 1 & & 1 & & 1 & 1 & \\
\hline Total & 2046 & 1873 & 155 & 18 & 2013 & 8 & 10 \\
\hline NT & 19 & 13 & 6 & & 13 & 3 & \\
\hline Grand Total & 2065 & 1886 & 161 & 18 & 2026 & 11 & 10 \\
\hline
\end{tabular}

1 


\section{Table 6(on next page)}

Investigation of discordant isolates in the Validation Set 


\begin{tabular}{|c|c|c|c|c|}
\hline & \multicolumn{2}{|c|}{ Slide Agglutination } & \multicolumn{2}{|c|}{ WGS } \\
\hline Isolate & Initial & Repeat & Initial & Repeat \\
\hline PHESPV0001 & $18 \mathrm{~F}$ & 3 & 3 & \\
\hline PHESPV0002 & 091 & Novel 9 pattern & Novel 9 & $\begin{array}{c}\text { Novel } \\
9\end{array}$ \\
\hline PHESPV0012 & 09A & $09 \mathrm{~V}$ & $09 \mathrm{~V}$ & \\
\hline PHESPV0013 & 09A & $09 \mathrm{~V}$ & $09 \mathrm{~V}$ & \\
\hline PHESPV0016 & 12B & $12 \mathrm{~F}$ & $12 \mathrm{~F}$ & $12 \mathrm{~F}$ \\
\hline PHESPV0024 & $35 \mathrm{C}$ & $35 B$ & $35 B$ & \\
\hline PHESPV0025 & 07A & $07 \mathrm{~F}$ & 07F & \\
\hline PHESPV0027 & 09A & $09 \mathrm{~V}$ & $09 \mathrm{~V}$ & \\
\hline PHESPV0029 & 18B & $18 \mathrm{C}$ & $18 \mathrm{C}$ & \\
\hline PHESPV0070 & 06B & 06D & 06D & \\
\hline PHESPV0071 & NT & 27 & 27 & \\
\hline PHESPV0101 & 09N & 09N & $23 B$ & 09N \\
\hline PHESPV0112 & 06B & $17 \mathrm{~F}$ & $17 \mathrm{~F}$ & \\
\hline PHESPV0121 & 09N & 8 & 8 & \\
\hline PHESPV0128 & 1 & $15 \mathrm{~A}$ & $15 A$ & \\
\hline PHESPV0174 & 09A & 09V & $09 \mathrm{~V}$ & \\
\hline PHESPV0189 & $\underline{2}$ & $11 \mathrm{~A}$ & $11 \mathrm{~A}$ & \\
\hline PHESPV0194 & 29 & $22 \mathrm{~F}$ & $22 \mathrm{~F}$ & \\
\hline PHESPV0197 & 29 & $35 B$ & $35 B$ & \\
\hline PHESPV0200 & $\underline{29}$ & 34 & 34 & \\
\hline PHESPV0204 & 36 & $22 \mathrm{~F}$ & $22 \mathrm{~F}$ & \\
\hline PHESPV0209 & $23 F$ & $23 B$ & $23 B$ & \\
\hline PHESPV0211 & 29 & $35 B$ & $35 B$ & \\
\hline PHESPV0235 & NT & $35 B$ & $35 B$ & \\
\hline PHESPV0303 & 07A & $07 \mathrm{~F}$ & 07F & \\
\hline PHESPV0322 & 15A & $15 B / C$ & $\begin{array}{c}15 B \\
\text { Serogroup }\end{array}$ & \\
\hline PHESPV0348 & $24 A$ & $24 \mathrm{~F}$ & 24 & \\
\hline PHESPV0349 & $35 A$ & $35 B$ & $35 B$ & \\
\hline & & & Serogroup & \\
\hline PHESPV0380 & 24A & $24 \mathrm{~F}$ & 24 & \\
\hline PHESPV0438 & 15A & 15B/C & 15B & \\
\hline PHESPV0448 & $15 F$ & $15 B$ & 15B & \\
\hline PHESPV0458 & $23 F$ & $23 B$ & $23 B$ & \\
\hline PHESPV0489 & $35 A$ & $35 B$ & $35 B$ & \\
\hline PHESPV0518 & $35 A$ & $35 B$ & $35 B$ & \\
\hline PHESPV0525 & $35 A$ & $35 B$ & $35 B$ & \\
\hline PHESPV0526 & 35A & $35 B$ & $35 B$ & \\
\hline PHESPV0537 & $15 A$ & $15 B / C$ & $15 B / C$ & \\
\hline PHESPV0555 & 06B & $06 C$ & $06 C$ & \\
\hline PHESPV0556 & $23 \mathrm{~F}$ & $23 B$ & $23 B$ & \\
\hline PHESPV0557 & $35 A$ & $35 B$ & $35 B$ & \\
\hline
\end{tabular}




\begin{tabular}{|c|c|c|c|}
\hline PHESPV0558 & $11 C$ & $11 \mathrm{~A}$ & $11 \mathrm{~A}$ \\
\hline PHESPV0562 & $15 F$ & $15 B$ & $15 B$ \\
\hline PHESPV0563 & $33 A$ & $33 \mathrm{~F}$ & $33 F$ \\
\hline PHESPV0566 & $23 F$ & $23 B$ & 23B1 \\
\hline PHESPV0582 & 19A & $19 F$ & $19 \mathrm{~F}$ \\
\hline PHESPV0586 & 06B & $06 C$ & $06 \mathrm{C}$ \\
\hline PHESPV0591 & $35 A$ & $35 B$ & $35 \mathrm{~B}$ \\
\hline PHESPV0605 & $35 A$ & $35 B$ & $35 B$ \\
\hline PHESPV0608 & $\underline{20}$ & $11 \mathrm{~A}$ & $11 \mathrm{~A}$ \\
\hline PHESPV0613 & $35 A$ & $35 B$ & $35 B$ \\
\hline PHESPV0616 & 06B & $33 \mathrm{~F}$ & $33 F$ \\
\hline PHESPV0624 & $35 A$ & $35 B$ & $35 B$ \\
\hline PHESPV0654 & 35A & $35 B$ & $35 B$ \\
\hline PHESPV0663 & $35 A$ & $35 B$ & $35 B$ \\
\hline PHESPV0667 & 12B & $12 \mathrm{~F}$ & $12 \mathrm{~F}$ \\
\hline PHESPV0669 & $35 A$ & $35 B$ & $35 B$ \\
\hline PHESPV0678 & $23 F$ & $23 B$ & $23 B$ \\
\hline PHESPV0681 & 12B & $12 \mathrm{~F}$ & $12 \mathrm{~F}$ \\
\hline PHESPV0691 & NT & 37 & 37 \\
\hline PHESPV0698 & $\underline{24 \mathrm{~F}}$ & $07 \mathrm{~F}$ & $07 \mathrm{~F}$ \\
\hline PHESPV0700 & $\underline{07 F}$ & 20 & 20 \\
\hline PHESPV0744 & $10 A$ & $16 \mathrm{~F}$ & $16 \mathrm{~F}$ \\
\hline PHESPV0753 & $35 A$ & $35 B$ & $35 B$ \\
\hline PHESPV0761 & 12B & $12 \mathrm{~F}$ & $12 \mathrm{~F}$ \\
\hline PHESPV0773 & $35 A$ & $35 B$ & $35 B$ \\
\hline PHESPV0779 & 12B & $12 \mathrm{~F}$ & $12 \mathrm{~F}$ \\
\hline PHESPV0780 & 12B & $12 \mathrm{~F}$ & $12 \mathrm{~F}$ \\
\hline PHESPV0794 & 12B & $12 \mathrm{~F}$ & $12 \mathrm{~F}$ \\
\hline PHESPV0796 & 12B & $12 \mathrm{~F}$ & $12 \mathrm{~F}$ \\
\hline PHESPV0797 & $12 B$ & $12 \mathrm{~F}$ & $12 \mathrm{~F}$ \\
\hline PHESPV0804 & $35 A$ & $35 B$ & $35 B$ \\
\hline PHESPV0805 & 33A & $33 \mathrm{~F}$ & $33 \mathrm{~F}$ \\
\hline PHESPV0812 & $10 \mathrm{~B}$ & $10 \mathrm{~F}$ & $10 \mathrm{~F}$ \\
\hline PHESPV0820 & $12 \mathrm{~A}$ & $12 \mathrm{~F}$ & $12 \mathrm{~F}$ \\
\hline PHESPV0836 & $23 F$ & $23 B$ & $23 B$ \\
\hline PHESPV0839 & $11 C$ & $11 \mathrm{~A}$ & $11 \mathrm{~A}$ \\
\hline PHESPV0840 & 33A & $33 \mathrm{~F}$ & $33 \mathrm{~F}$ \\
\hline PHESPV0843 & $35 A$ & $35 B$ & $35 B$ \\
\hline PHESPV0845 & $23 F$ & $23 \mathrm{~A}$ & $23 \mathrm{~A}$ \\
\hline PHESPV0854 & 06B & 06A & $06 \mathrm{~A}$ \\
\hline PHESPV0861 & $35 A$ & $35 B$ & $35 B$ \\
\hline PHESPV0862 & $\underline{18 \mathrm{~F}}$ & $23 B$ & $23 \mathrm{~B} 1$ \\
\hline PHESPV0888 & $11 C$ & $11 \mathrm{~A}$ & $11 \mathrm{~A}$ \\
\hline PHESPV0891 & $11 C$ & $11 \mathrm{~A}$ & $11 \mathrm{~A}$ \\
\hline PHESPV0894 & $\underline{37}$ & $16 \mathrm{~F}$ & $16 \mathrm{~F}$ \\
\hline
\end{tabular}




\begin{tabular}{|c|c|c|c|}
\hline PHESPV0898 & $\underline{19 A}$ & 3 & 3 \\
\hline PHESPV0912 & $\underline{14}$ & $15 B$ & 15B \\
\hline PHESPV1001 & 29 & $35 B$ & $35 B$ \\
\hline PHESPV1005 & 14 & $12 \mathrm{~F}$ & $12 \mathrm{~F}$ \\
\hline PHESPV1014 & $35 A$ & $35 B$ & $35 B$ \\
\hline PHESPV1017 & $23 \mathrm{~F}$ & $35 \mathrm{~F}$ & $35 \mathrm{~F}$ \\
\hline PHESPV1018 & $\underline{14}$ & $23 \mathrm{~A}$ & $23 \mathrm{~A}$ \\
\hline PHESPV1020 & $23 F$ & $23 B$ & 23B1 \\
\hline PHESPV1084 & $\underline{20}$ & $22 \mathrm{~F}$ & $22 \mathrm{~F}$ \\
\hline PHESPV1140 & $12 F$ & $12 \mathrm{~B}$ & $12 B$ \\
\hline PHESPV1168 & $15 \mathrm{~A}$ & $15 \mathrm{~A}$ & $19 F$ \\
\hline PHESPV1178 & $\underline{06 C}$ & $23 B$ & $23 B 1$ \\
\hline & & & Serogroup \\
\hline PHESPV1200 & $\underline{07 B}$ & $24 \mathrm{~F}$ & 24 \\
\hline PHESPV1208 & $12 F$ & $12 \mathrm{~B}$ & $12 B$ \\
\hline PHESPV1244 & $\underline{23 \mathrm{~A}}$ & $15 \mathrm{~A}$ & $15 \mathrm{~A}$ \\
\hline PHESPV1283 & $12 \mathrm{~F}$ & $12 \mathrm{~B}$ & $12 B$ \\
\hline PHESPV1390 & $\underline{07 F}$ & 31 & 31 \\
\hline PHESPV1401 & $10 \mathrm{~A}$ & $22 \mathrm{~F}$ & $22 \mathrm{~F}$ \\
\hline PHESPV1406 & $12 \mathrm{~F}$ & $12 \mathrm{~B}$ & $12 B$ \\
\hline PHESPV1413 & $19 \mathrm{~A}$ & 8 & 8 \\
\hline PHESPV1418 & 06D & $06 C$ & $06 C$ \\
\hline PHESPV1648 & $23 F$ & $23 B$ & $23 B$ \\
\hline PHESPV1650 & $23 F$ & $23 B$ & 23B1 \\
\hline PHESPV1652 & 07A & $07 \mathrm{~F}$ & $07 \mathrm{~F}$ \\
\hline PHESPV1654 & $\underline{35 \mathrm{~F}}$ & 34 & 34 \\
\hline PHESPV1668 & $\underline{11 \mathrm{~A}}$ & $16 \mathrm{~F}$ & $16 \mathrm{~F}$ \\
\hline PHESPV1716 & 07A & $07 \mathrm{~F}$ & $07 \mathrm{~F}$ \\
\hline PHESPV1734 & $\underline{11 \mathrm{~A}}$ & $16 \mathrm{~F}$ & $\begin{array}{c}16 \mathrm{~F} \\
\text { Serogroup }\end{array}$ \\
\hline PHESPV1790 & $\underline{20}$ & $24 \mathrm{~F}$ & 24 \\
\hline PHESPV1809 & $\underline{28 F}$ & $23 B$ & $23 B$ \\
\hline PHESPV1845 & $15 C$ & $15 \mathrm{~A}$ & $15 A$ \\
\hline PHESPV1847 & $15 C$ & $15 \mathrm{~A}$ & $15 A$ \\
\hline PHESPV1848 & $15 C$ & $15 \mathrm{~A}$ & $15 A$ \\
\hline PHESPV1864 & $\underline{5}$ & 4 & 4 \\
\hline PHESPV1868 & $15 C$ & $15 \mathrm{~A}$ & $15 A$ \\
\hline PHESPV1869 & $15 C$ & $15 \mathrm{~A}$ & $15 A$ \\
\hline PHESPV1874 & $15 C$ & $15 \mathrm{~A}$ & $15 A$ \\
\hline PHESPV1883 & 29 & $35 B$ & $35 B$ \\
\hline PHESPV1919 & 29 & $35 B$ & $35 B$ \\
\hline PHESPV1935 & 29 & $35 B$ & $35 B$ \\
\hline PHESPV1941 & $10 F$ & $10 A$ & $10 A$ \\
\hline PHESPV1951 & $35 C$ & $35 B$ & $35 B$ \\
\hline PHESPV2005 & $12 B$ & $12 \mathrm{~F}$ & $12 \mathrm{~F}$ \\
\hline
\end{tabular}




\begin{tabular}{|c|c|c|c|}
\hline PHESPV2007 & 12B & $12 \mathrm{~F}$ & $12 \mathrm{~F}$ \\
\hline PHESPV2017 & 23B & $23 \mathrm{~A}$ & $23 \mathrm{~A}$ \\
\hline PHESPV2018 & 19C & $19 \mathrm{~A}$ & $19 \mathrm{~A}$ \\
\hline PHESPV2028 & $\mathbf{1 2 B}$ & $12 \mathrm{~F}$ & $12 \mathrm{~F}$ \\
\hline PHESPV2032 & $\mathbf{2 9}$ & $35 \mathrm{~B}$ & $35 \mathrm{~B}$ \\
\hline PHESPV2035 & $\mathbf{1 2 B}$ & $12 \mathrm{~F}$ & $12 \mathrm{~F}$ \\
\hline PHESPV2039 & $\mathbf{1 2 B}$ & $12 \mathrm{~F}$ & $12 \mathrm{~F}$ \\
\hline PHESPV2042 & $\mathbf{1 2 B}$ & $12 \mathrm{~F}$ & $12 \mathrm{~F}$ \\
\hline PHESPV2043 & $07 \mathrm{C}$ & $33 \mathrm{~F}$ & $33 \mathrm{~F}$ \\
\hline PHESPV2049 & $\mathbf{1 2 B}$ & $12 \mathrm{~F}$ & $12 \mathrm{~F}$ \\
\hline PHESPV2052 & $\mathbf{1 2 B}$ & $12 \mathrm{~F}$ & $12 \mathrm{~F}$ \\
\hline PHESPV2062 & $\mathbf{1 2 B}$ & $12 \mathrm{~F}$ & $12 \mathrm{~F}$ \\
\hline PHESPV2063 & $\mathbf{0 7 C}$ & 40 & 40
\end{tabular}

1 